\title{
Synthesis and $\mu$-opioid activity of the primary metabolites of carfentanil
}

Fu-Lian Hsu' ${ }^{1}$, Andrew J. Walz ${ }^{1}$, James M. Myslinski ${ }^{1}$, Li Kong ${ }^{1}$, Michael G.Feasel ${ }^{1}$, Tyler D.P. Goralski ${ }^{1}$, Tim Rose ${ }^{2}$, Nicholas J. Cooper, ${ }^{2}$ Neil Roughley ${ }^{2}$, and Christopher M. Timperley ${ }^{2}$

1 United States Army CCDC Chemical Biological Center, Aberdeen Proving Ground, Maryland, USA

${ }^{2}$ Defence Science and Technology Laboratory (Dstl), Porton Down, Salisbury, Wiltshire UK

Contents:

Supporting Figure 1. ${ }^{1} \mathrm{H}$ NMR spectrum of M4 oxalate in D4-METHANOL. 2

Supporting Figure 2. ${ }^{13} \mathrm{C}$ NMR spectrum of M4 oxalate in D4-METHANOL. 2

Supporting Figure 3. ${ }^{1} \mathrm{H}$ NMR spectrum of M2 oxalate in D4-METHANOL. 3

Supporting Figure 4. ${ }^{13} \mathrm{C}$ NMR spectrum of M2 oxalate in D4-METHANOL. 3

Supporting Figure 5. ${ }^{1} \mathrm{H}$ NMR spectrum of M3 cis and M3 trans in D-CHLOROFORM. 4

Supporting Figure 6. ${ }^{13} \mathrm{C}$ NMR spectrum of M3 cis and M3 trans in D-CHLOROFORM. 5

$\begin{array}{lll}\text { Supporting Figure 7. }{ }^{1} \mathrm{H} \text { NMR spectrum of M5 oxalate in D4-METHANOL. } & 6\end{array}$

Supporting Figure 8. ${ }^{13} \mathrm{C}$ NMR spectrum of M5 oxalate in D4-METHANOL. 6

Supporting Figure 9. ${ }^{1} \mathrm{H}$ NMR spectrum of M6-para oxalate in D4-METHANOL. 7

Supporting Figure 10. ${ }^{13} \mathrm{C}$ NMR spectrum of M6-para oxalate in D4-METHANOL. $\quad 7$

Supporting Figure 11. ${ }^{1} \mathrm{H}$ NMR spectrum of M6-meta oxalate in D4-METHANOL. 8

Supporting Figure 12. ${ }^{13} \mathrm{C}$ NMR spectrum of M6-meta oxalate in D4-METHANOL. $\quad 8$

Supporting Figure 13. ${ }^{1} \mathrm{H}$ NMR spectrum of M6-ortho oxalate in D4-METHANOL. 9

Supporting Figure 14. ${ }^{13} \mathrm{C}$ NMR spectrum of M6-ortho oxalate in D4-METHANOL. $\quad 9$

$\begin{array}{ll}\text { Supporting Figure 15. Mass spectra for synthesized compounds. } & 10\end{array}$

Supporting Figure 16. Metabolic, UHPLC, and mass spectral methods and data for $\begin{array}{ll}\text { synthesized standards and metabolites. } & 14\end{array}$

Supporting Figure 17. MOR assay experimental methods. 16

Supporting Figure 18. Lance Ultra cAMP assay concentration-response curves. 17 
Supporting Figure 1. ${ }^{1} \mathrm{H}$ NMR spectrum of $\mathbf{M} 4$ oxalate in D4-METHANOL.

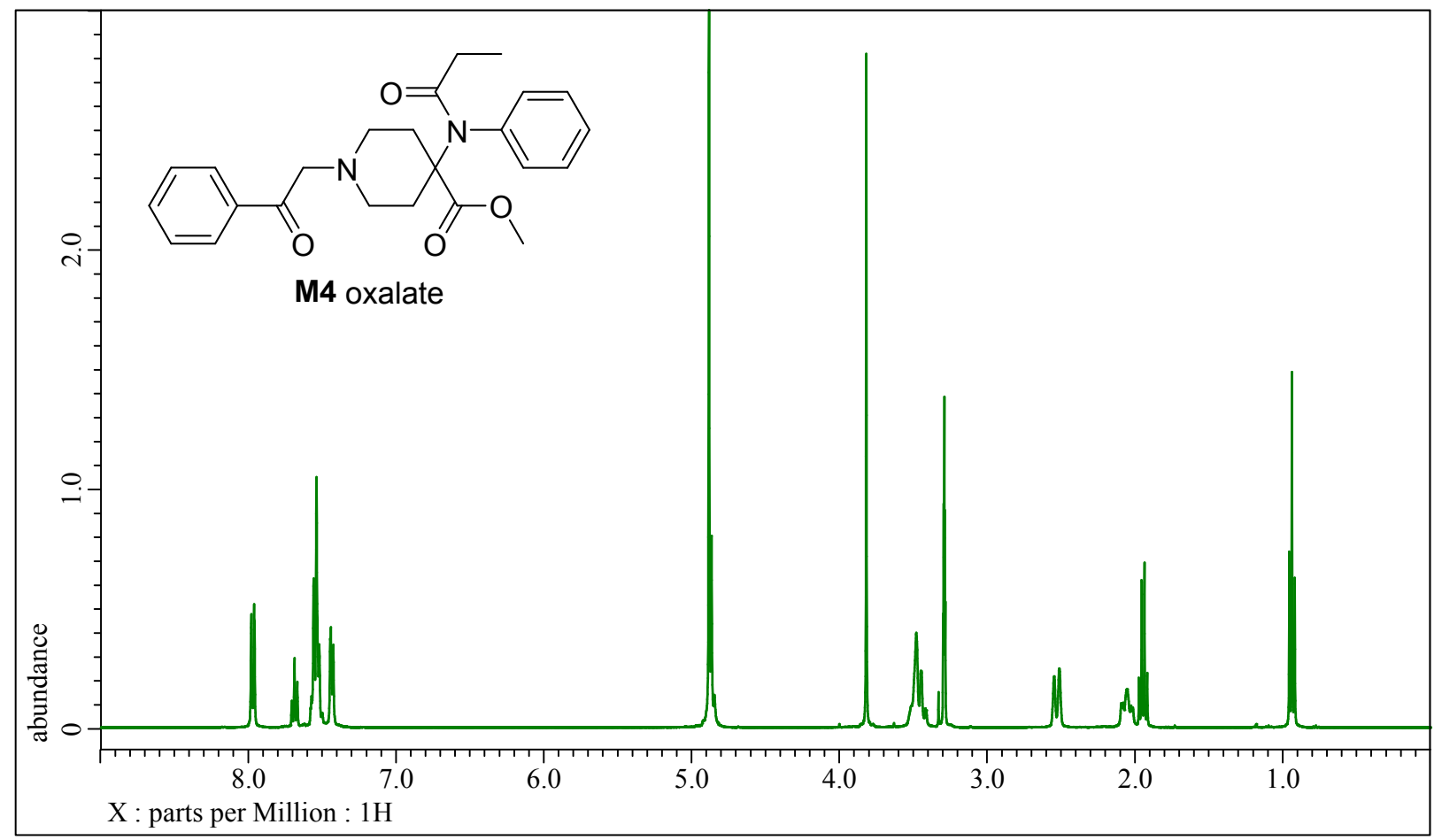

Supporting Figure 2. ${ }^{13} \mathrm{C}$ NMR spectrum of M4 oxalate in D4-METHANOL.

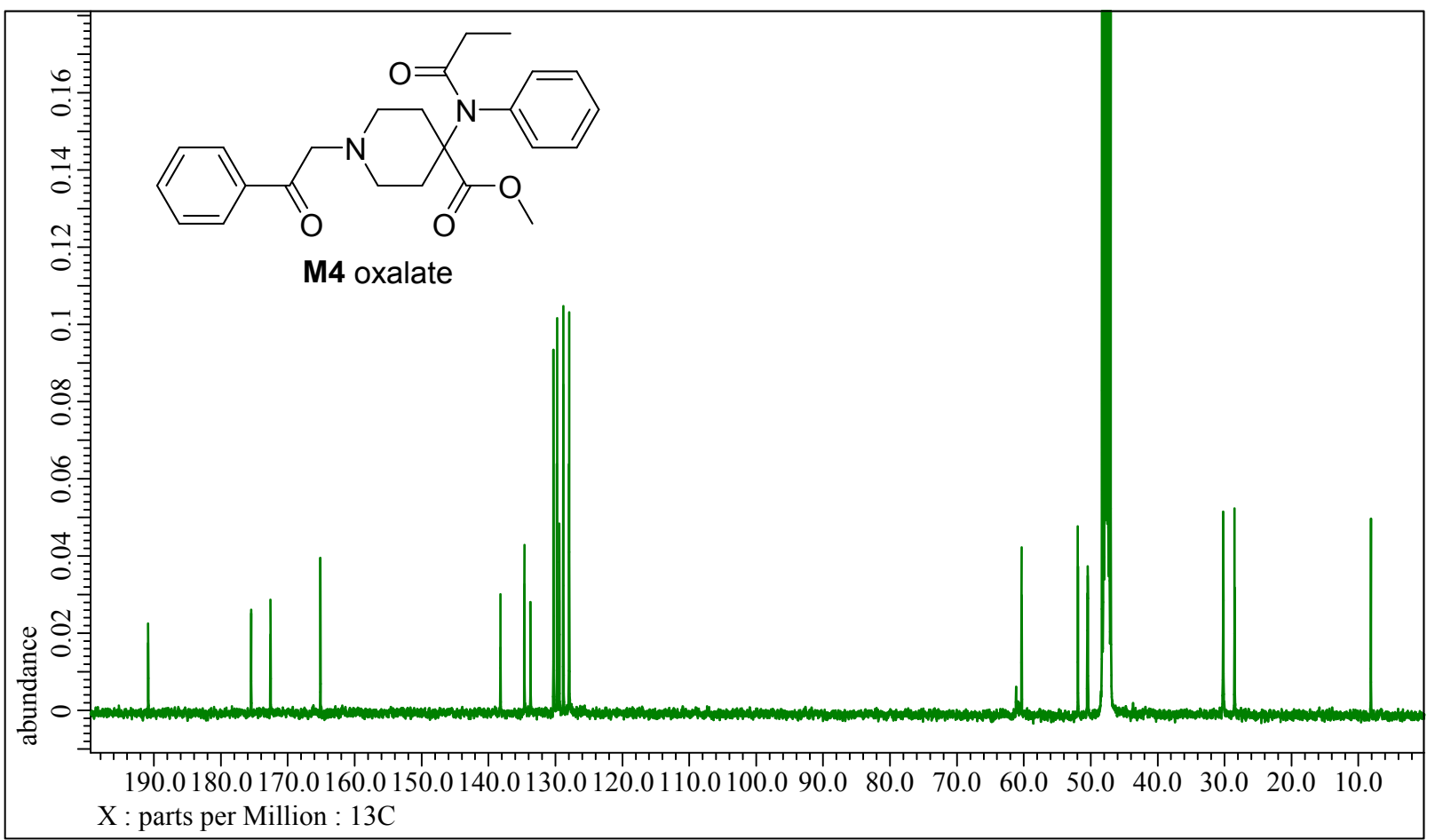


Supporting Figure 3. ${ }^{1} \mathrm{H}$ NMR spectrum of $\mathbf{M} 2$ oxalate in D4-METHANOL.

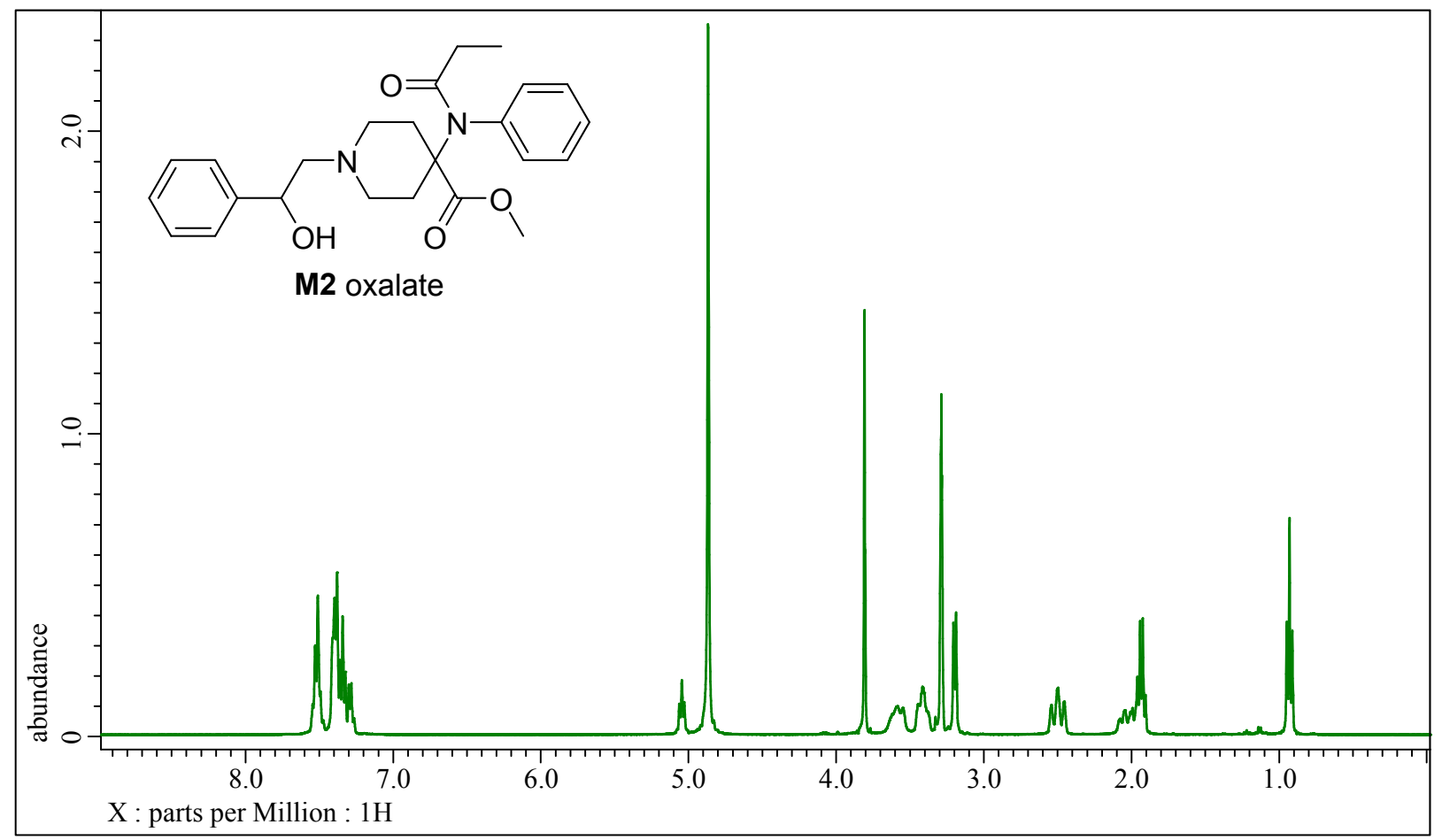

Supporting Figure 4. ${ }^{13} \mathrm{C}$ NMR spectrum of M2 oxalate in D4-METHANOL.

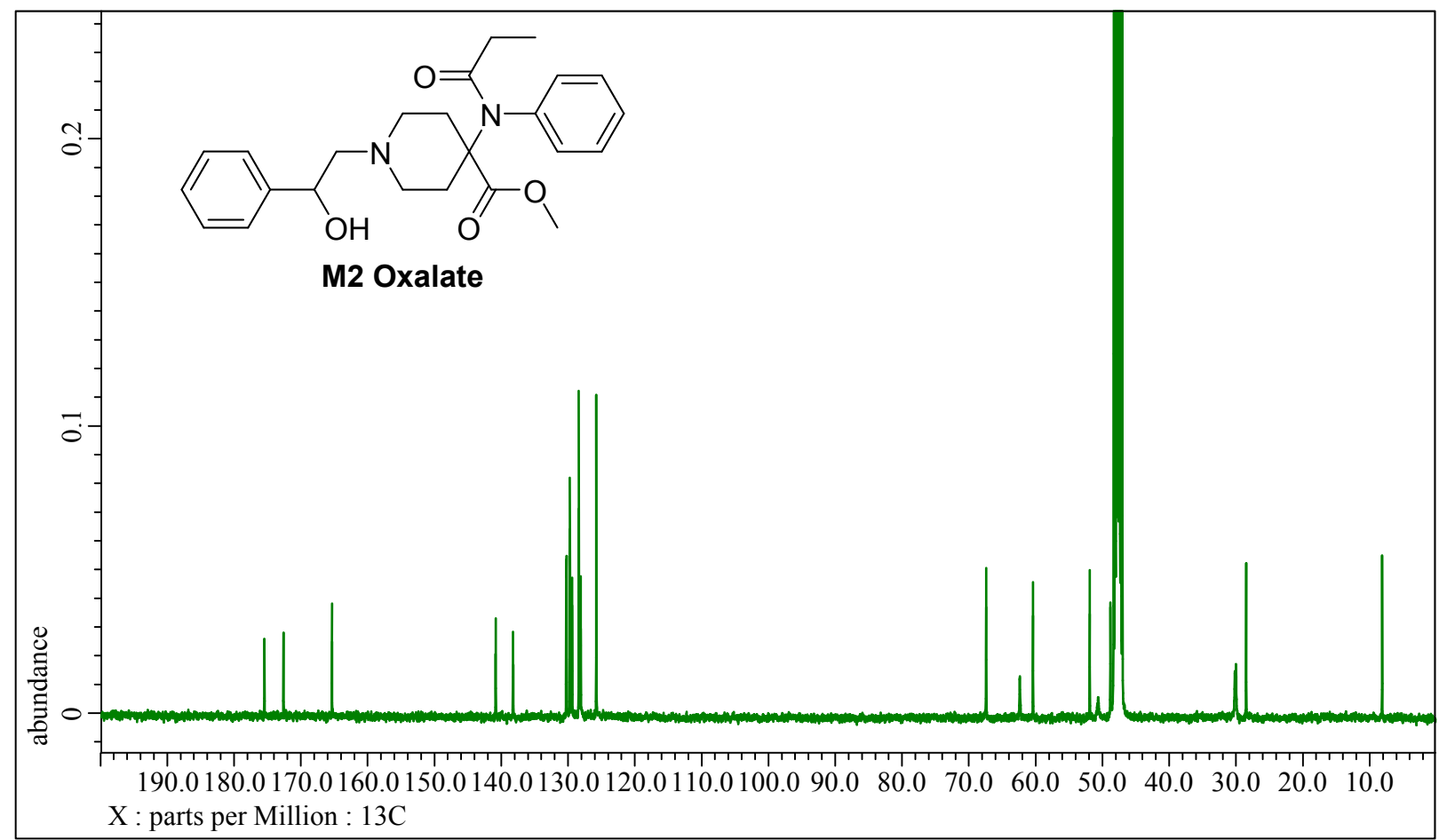


Supporting Figure 5. ${ }^{1} \mathrm{H}$ NMR spectrum of M3 cis and M3 trans in D-CHLOROFORM.
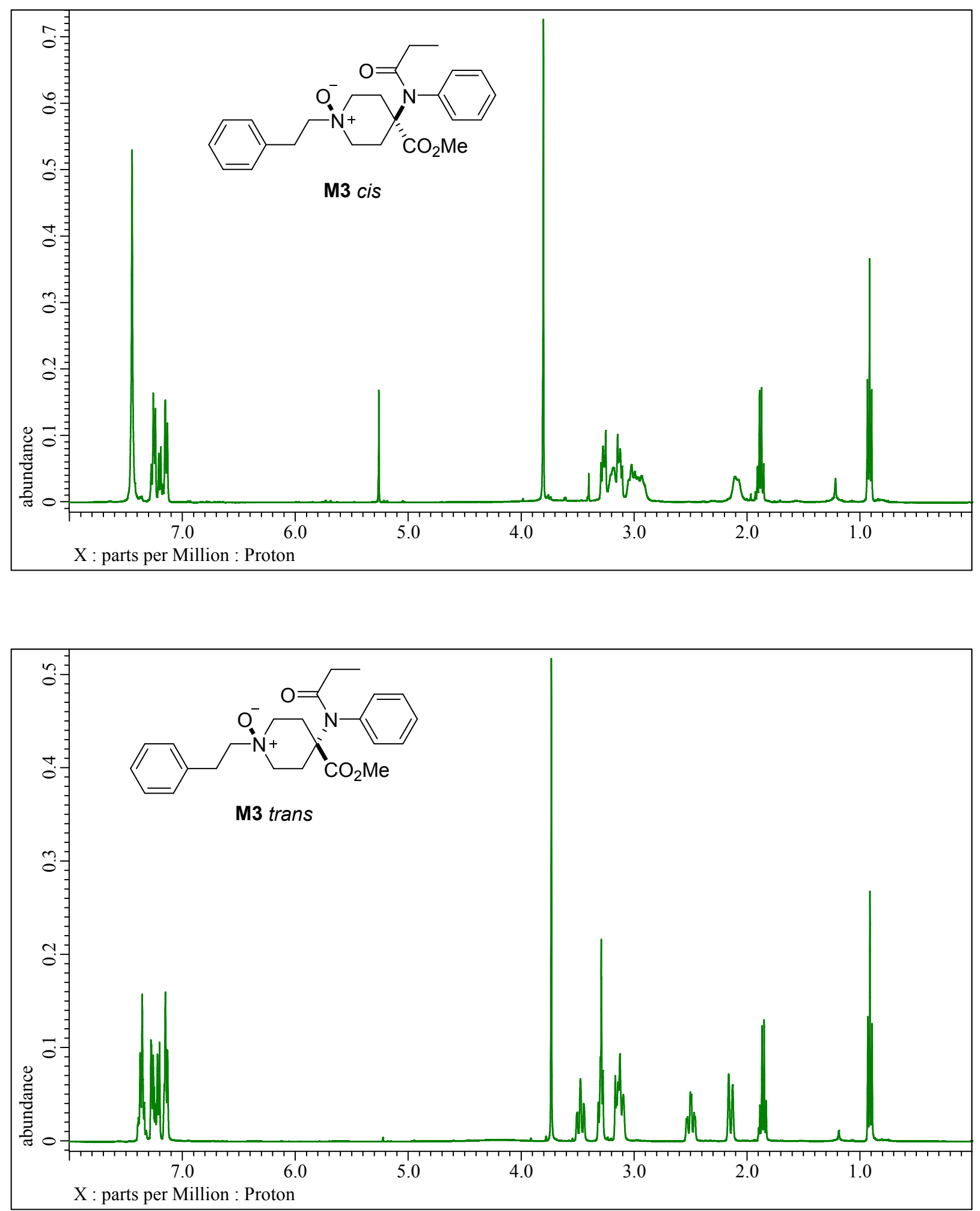
Supporting Figure 6. ${ }^{13} \mathrm{C}$ NMR spectrum of $\mathbf{M} 3$ cis and $\mathbf{M} 3$ trans in D-CHLOROFORM.
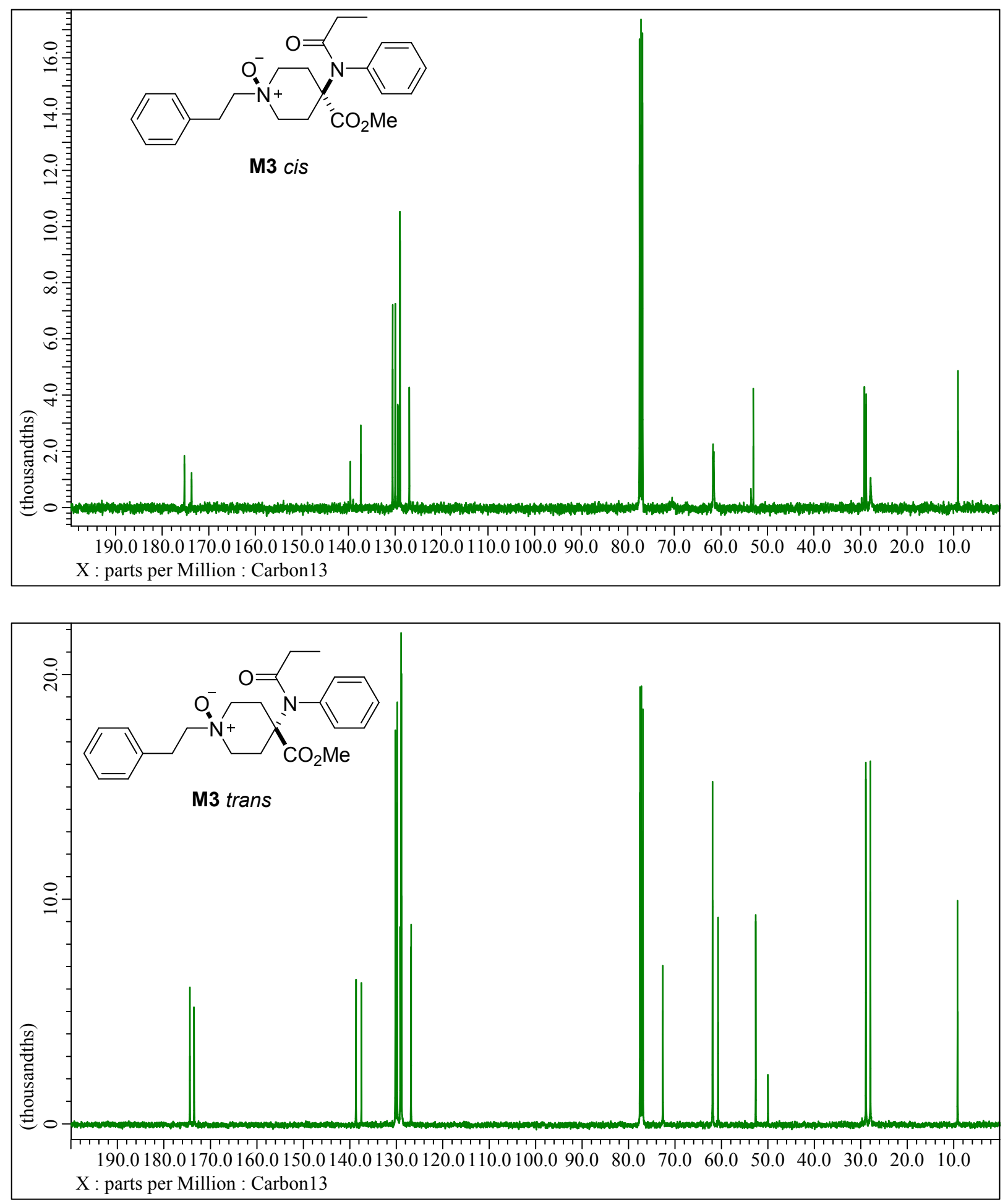
Supporting Figure 7. ${ }^{1} \mathrm{H}$ NMR spectrum of M5 oxalate in D4-METHANOL.

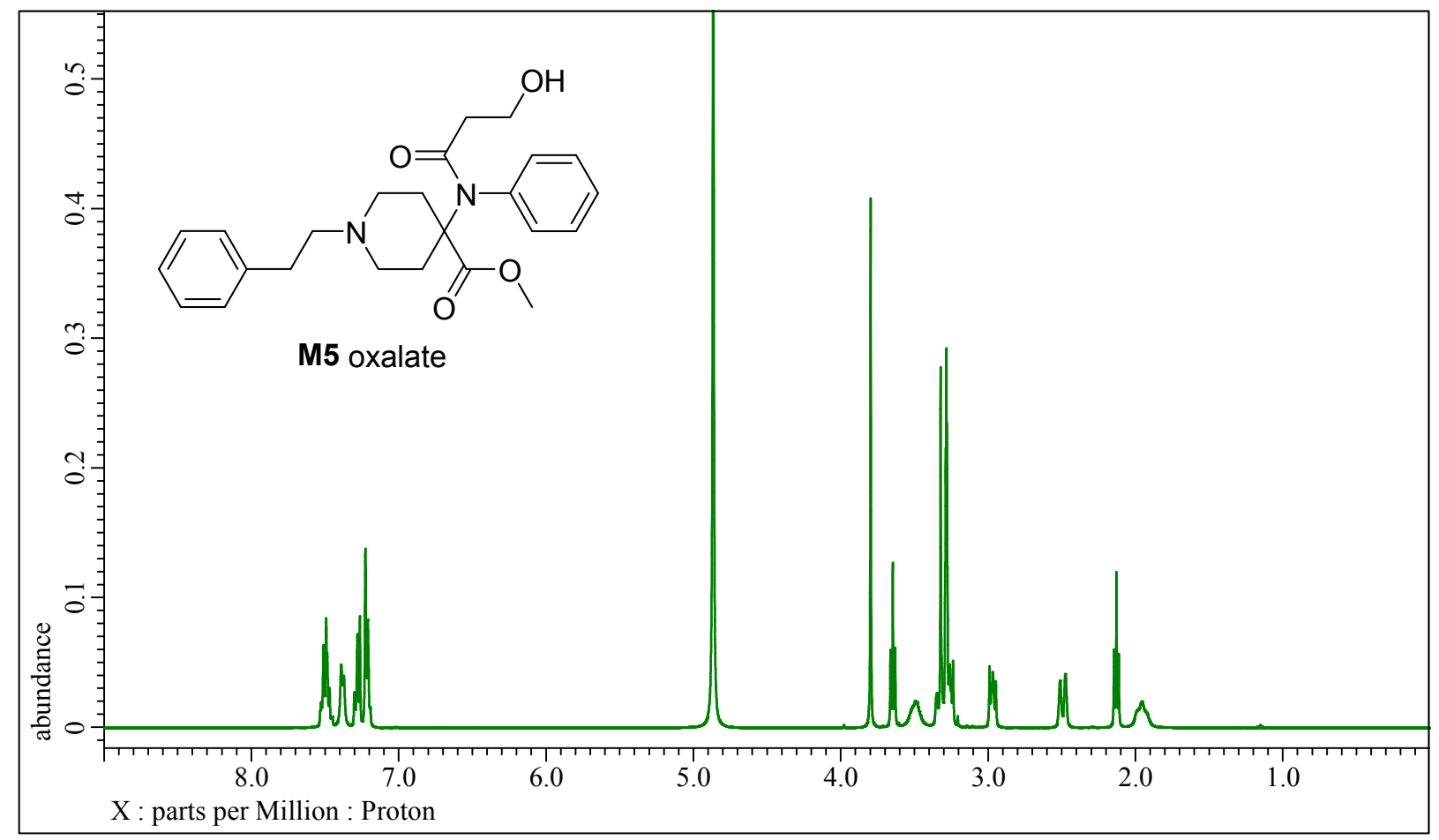

Supporting Figure 8. ${ }^{13} \mathrm{C}$ NMR spectrum of M5 oxalate in D4-METHANOL.

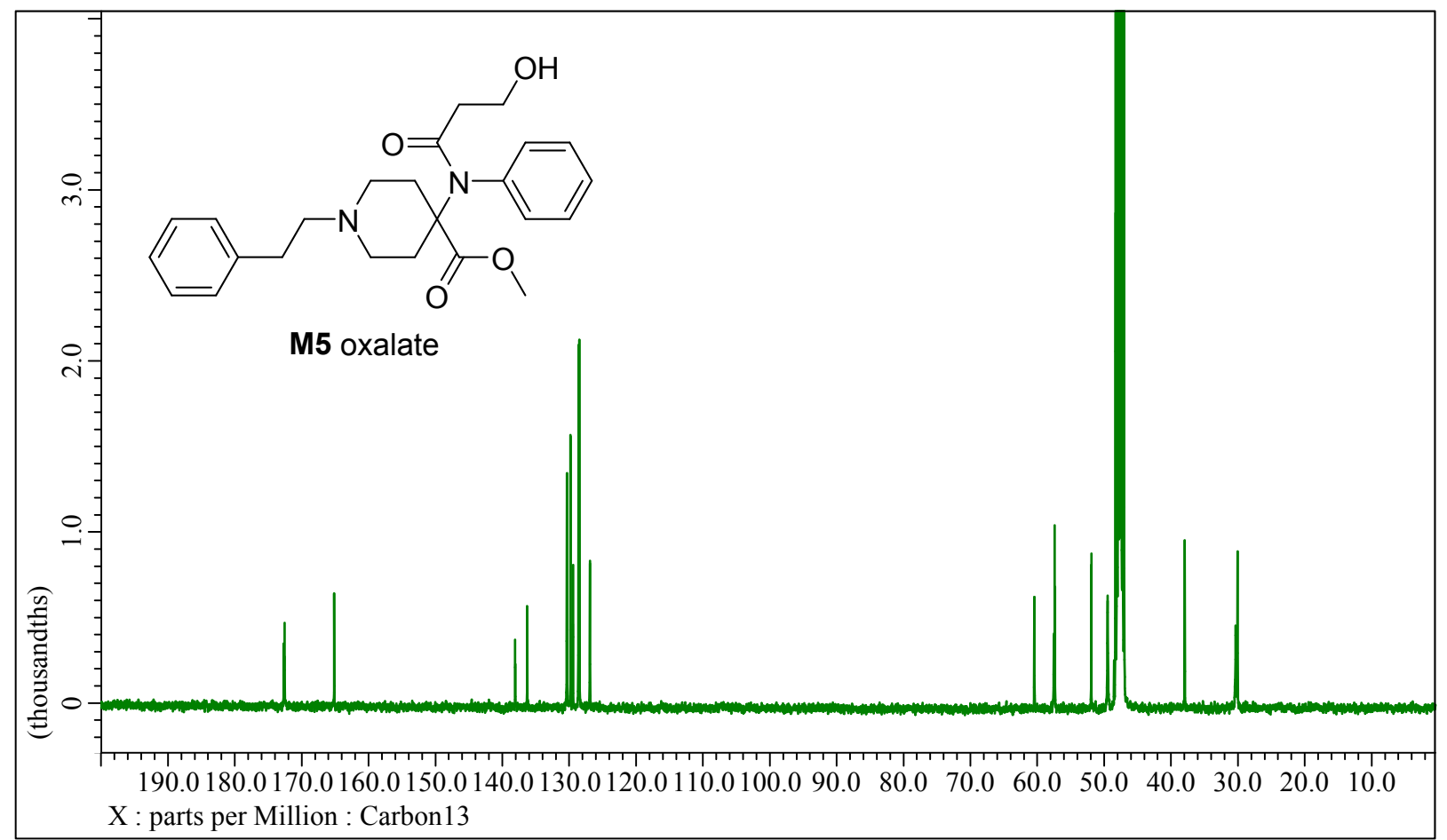


Supporting Figure 9. ${ }^{1} \mathrm{H}$ NMR spectrum of M6-para oxalate in D4-METHANOL.

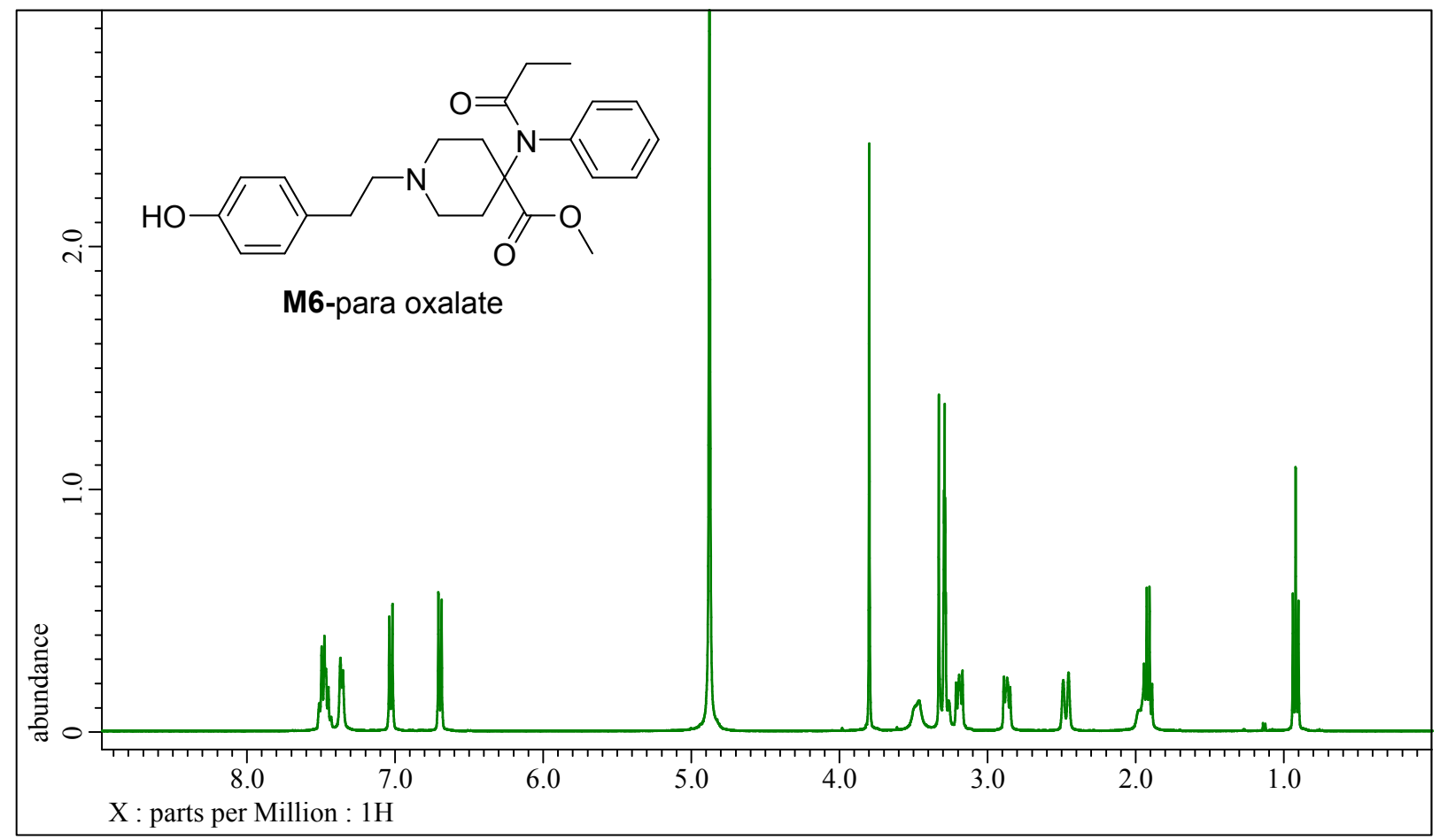

Supporting Figure 10. ${ }^{13} \mathrm{C}$ NMR spectrum of M6-para oxalate in D4-METHANOL.

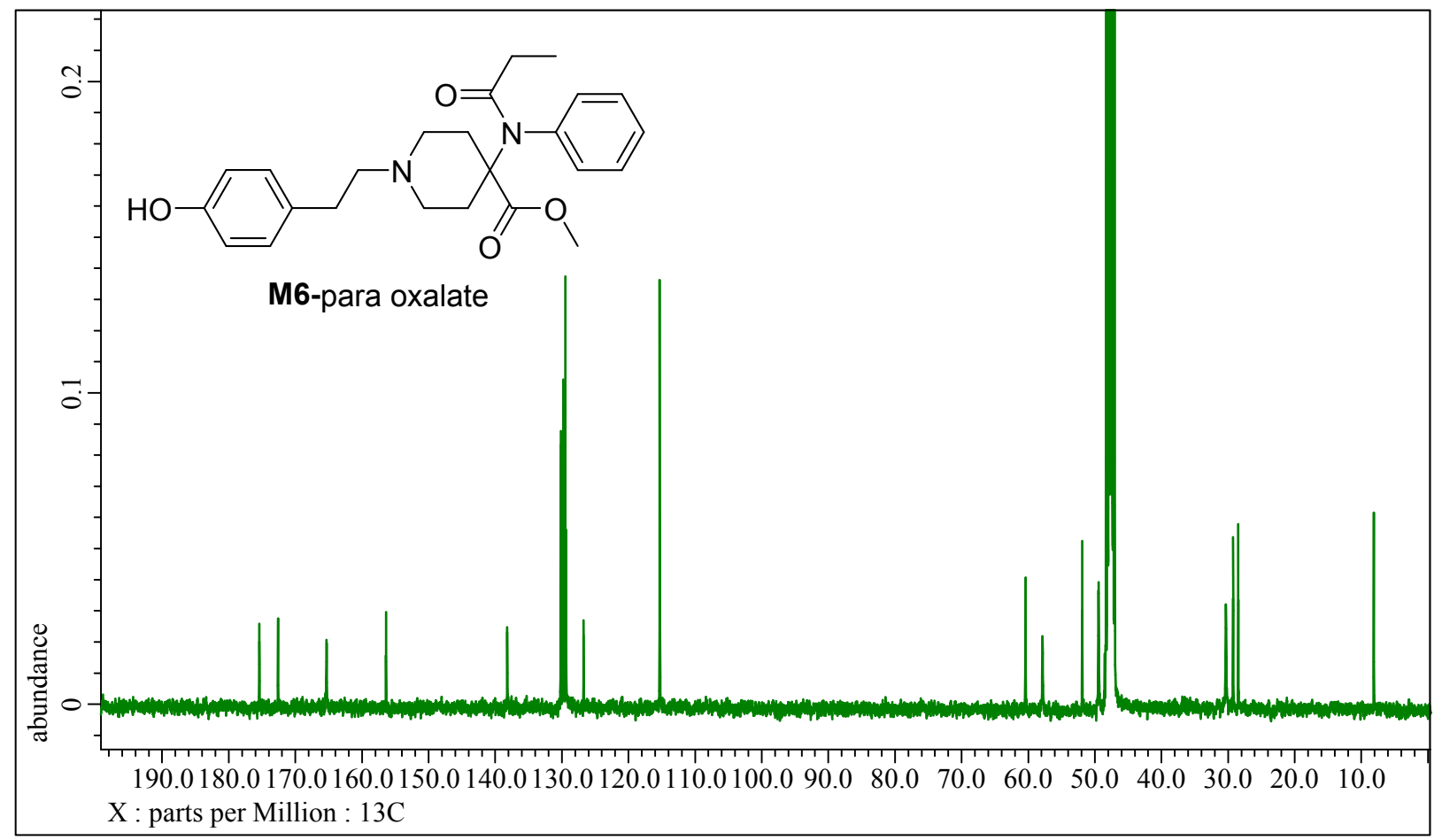


Supporting Figure 11. ${ }^{1} \mathrm{H}$ NMR spectrum of M6-meta oxalate in D4-METHANOL.

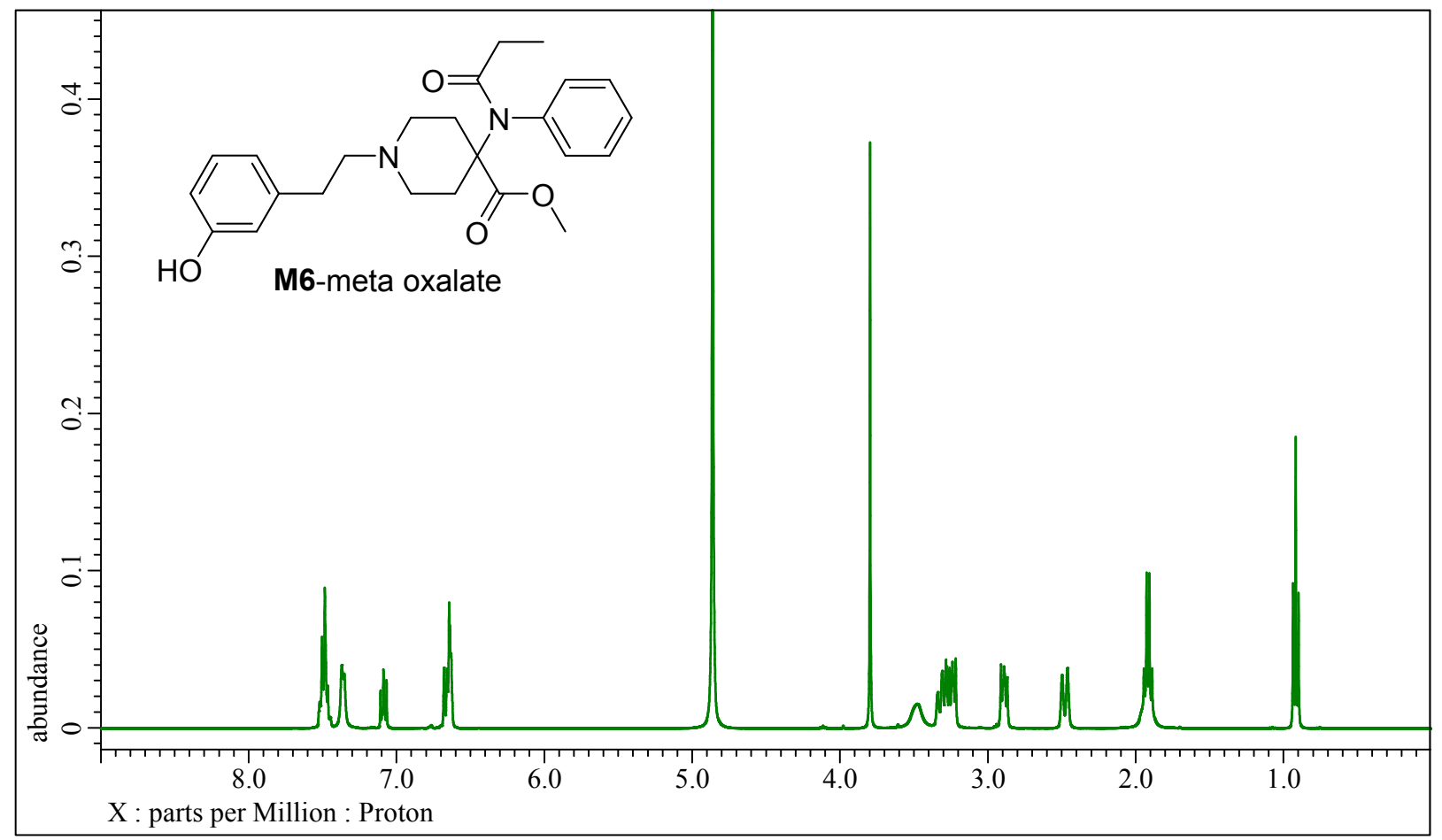

Supporting Figure 12. ${ }^{13} \mathrm{C}$ NMR spectrum of M6-meta oxalate in D4-METHANOL.

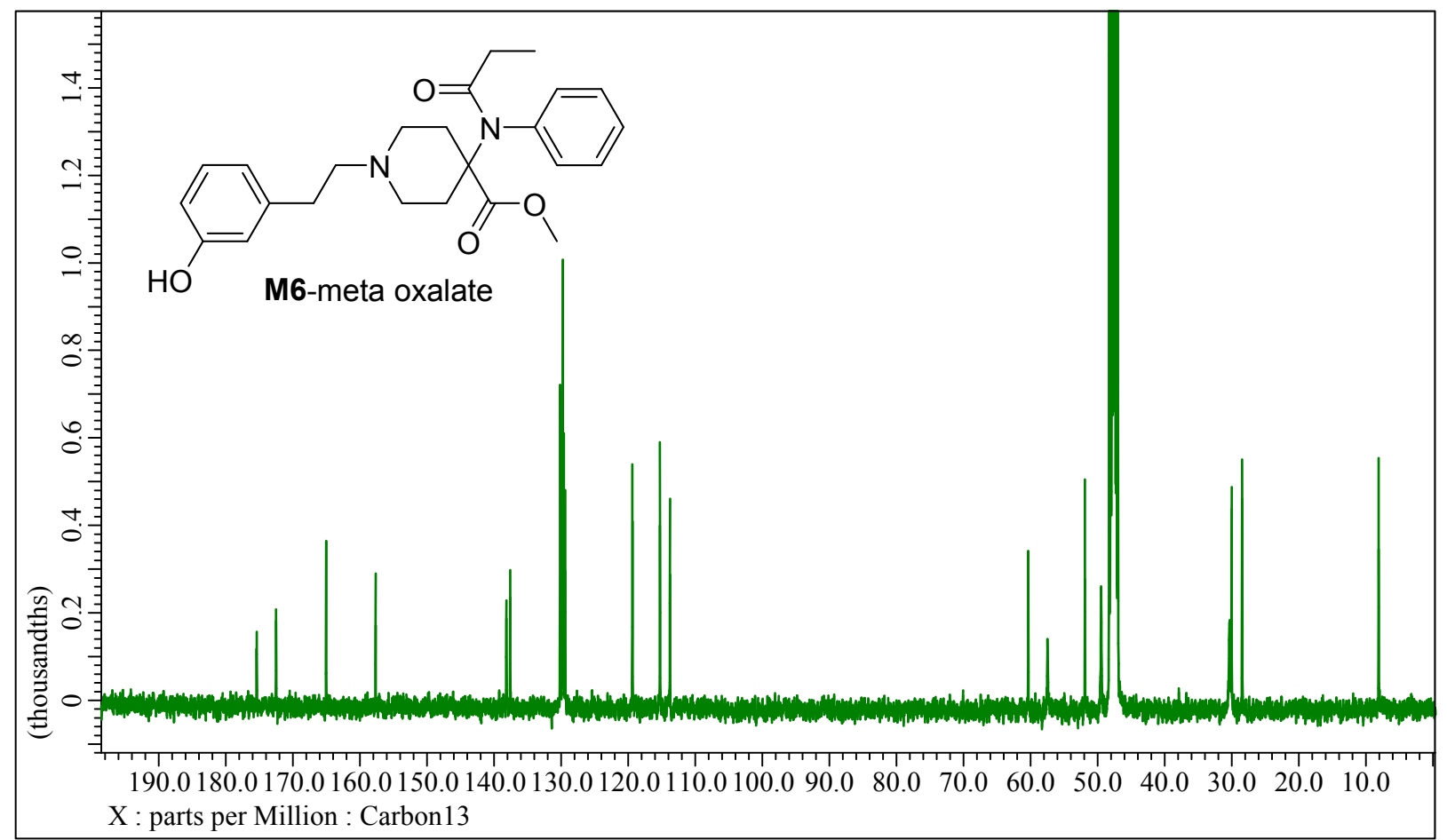


Supporting Figure 13. ${ }^{1} \mathrm{H}$ NMR spectrum of M6-ortho oxalate in D4-METHANOL.

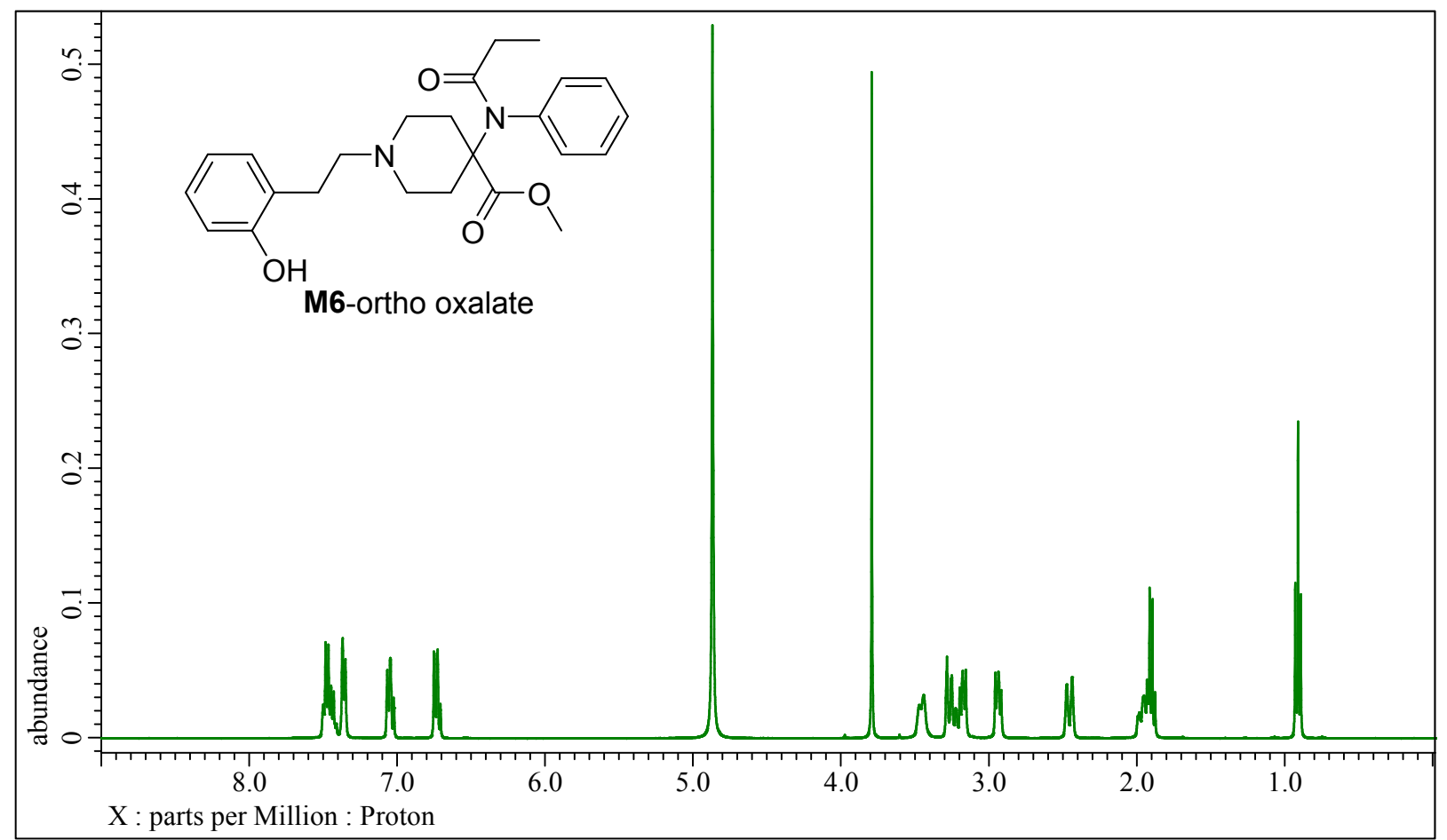

Supporting Figure 14. ${ }^{13} \mathrm{C}$ NMR spectrum of M6-ortho oxalate in D4-METHANOL.

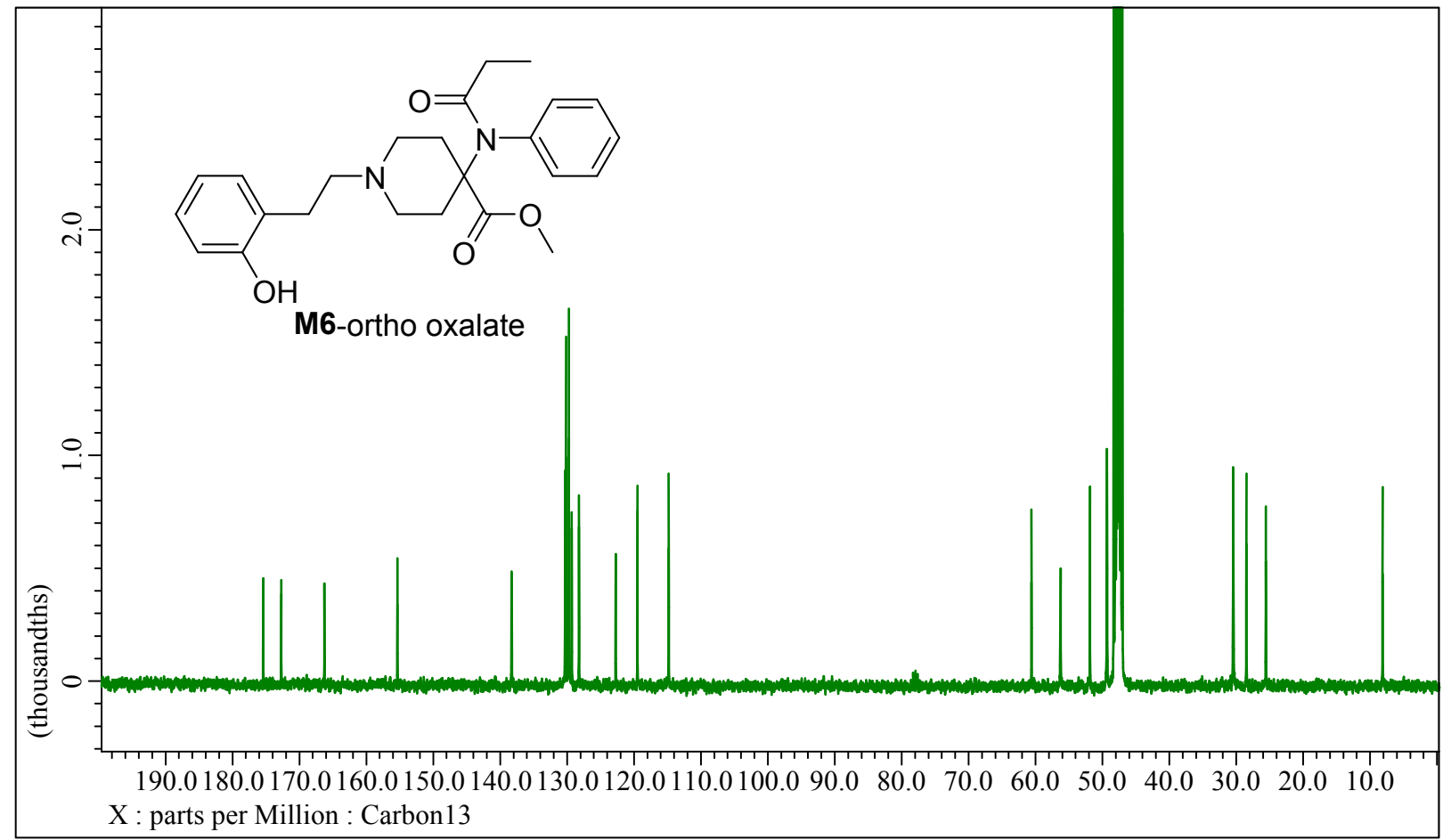


Supporting Figure 15. Mass spectra for synthesized compounds.

\section{M1 (m/z 291)}

RT: $5.67-10.19$ SM: $15 \mathrm{G}$

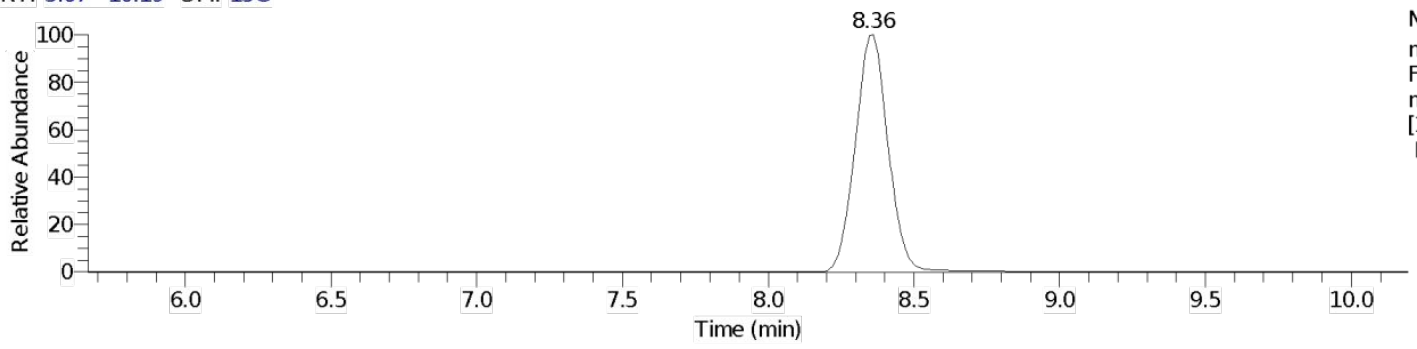

NL: 8.89E7 $\mathrm{m} / \mathrm{z}=290.50-291.50$ F: FTMS + pESI Full

ms $100.0000-800.0000]$ MS 18140B-fs-c

18140B-fS-c \#2583-2671 RT: 8.22-8.49 AV: 18 NL: $3.79 E 7$

F: FTMS + p ESI Full ms [100.0000-800.0000]

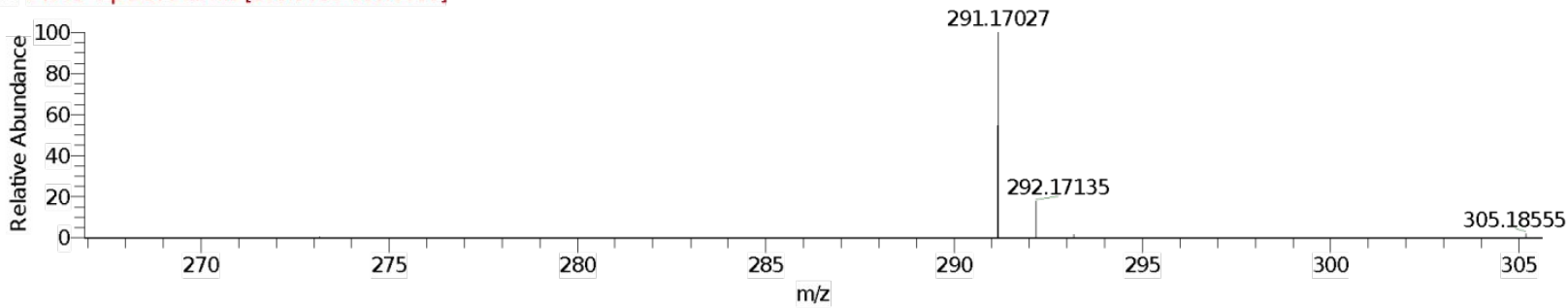

M2 (m/z 411)

RT: $9.40-13.48$ SM: $15 G$

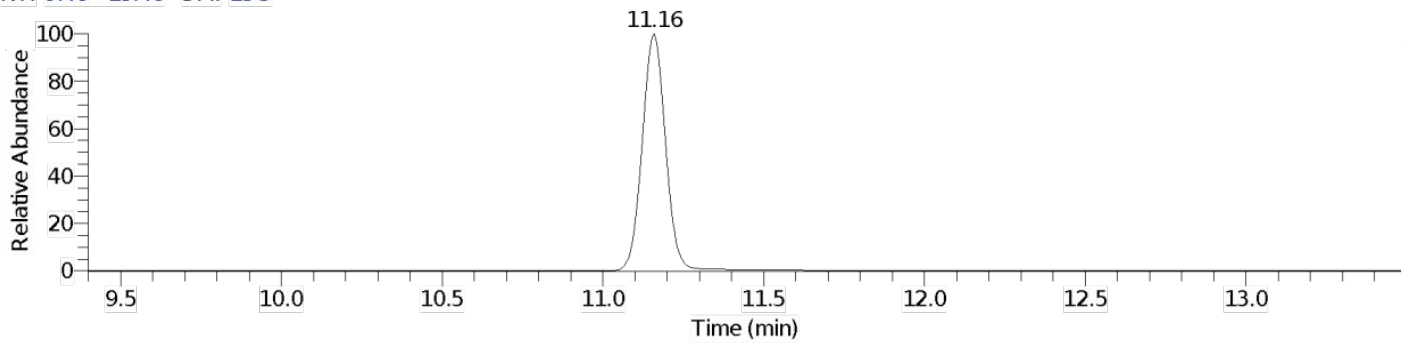

NL: $1.89 E 8$

TIC F: FTMS + c ESI

Full ms2

411.0000@hcd30.00

[50.0000-800.0000]

MS AW18046-1A

AW18046-1A \#2808-2865 RT: 11.07-11.29 AV: 29 NL: 8.04E7

F: FTMS + pESI Full ms [100.0000-800.0000]

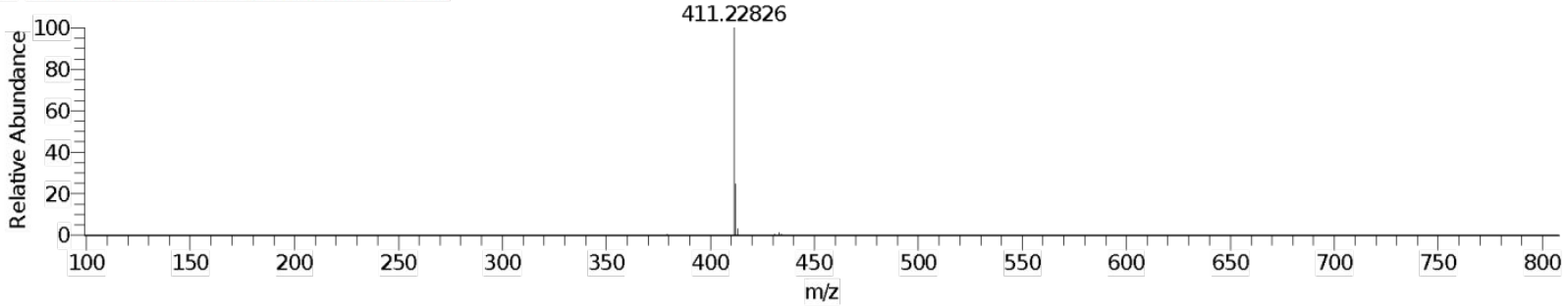




\section{M3 $\operatorname{cis}(\mathrm{m} / \mathrm{z}$ 411)}

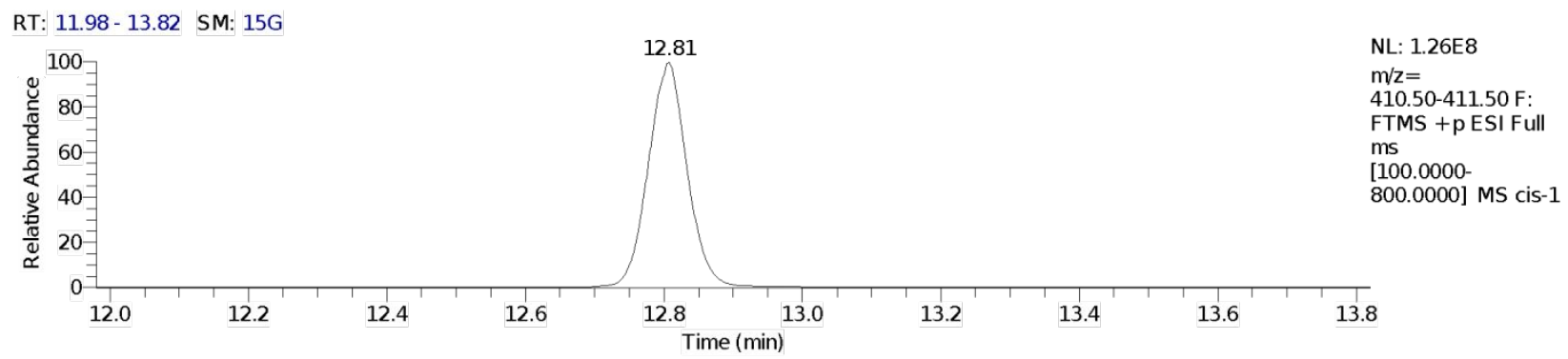

cis- $\# 2210-2215$ RT: $12.79-12.82$ AV: 6 SB: 121 8.90-9.29, 9.40-9.70 NL: $1.34 E 8$

F: FTMS + p ESI Full ms [100.0000-800.0000]

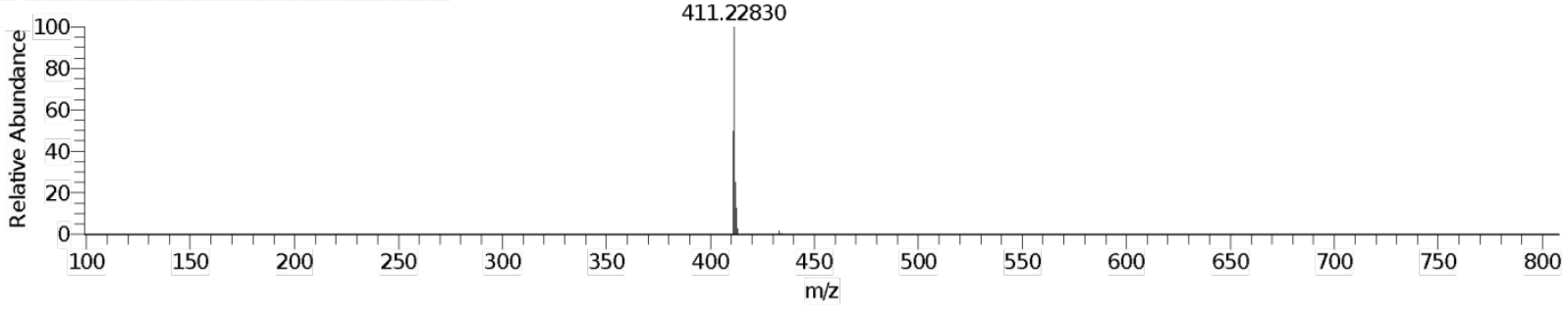

\section{M3 trans (m/z 411)}

\section{Trans}

RT: $11.98-13.82$ SM: $15 \mathrm{G}$

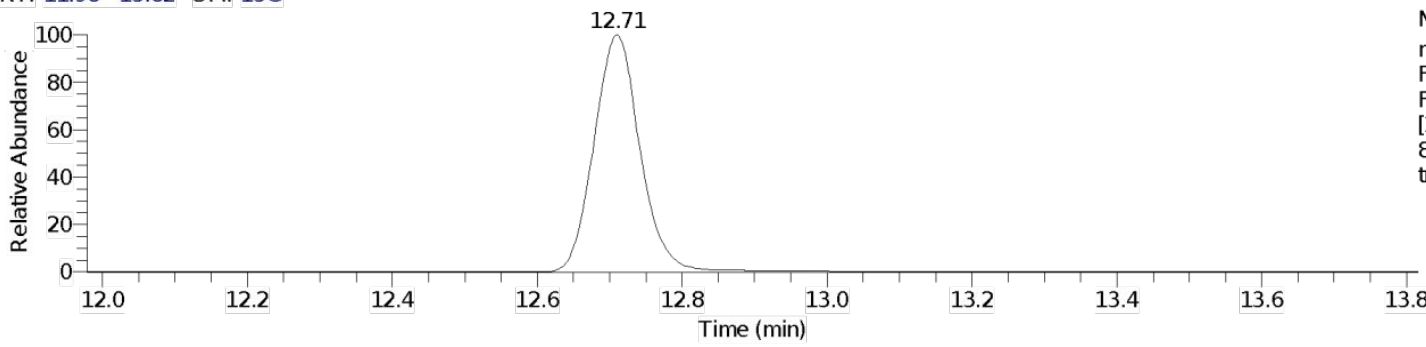

NL: $2.20 E 8$ $\mathrm{m} / \mathrm{z}=410.50-411.50$ F: FTMS + pESI

Full ms

[100.0000-

800.0000] MS

trans-2

trans-2 \#2202-2217 RT: 12.67-12.75 AV: 16 SB: 122 8.90-9.29, 9.40-9.70 NL: 1.59E8

F: FTMS + pESI Full ms [100.0000-800.0000]

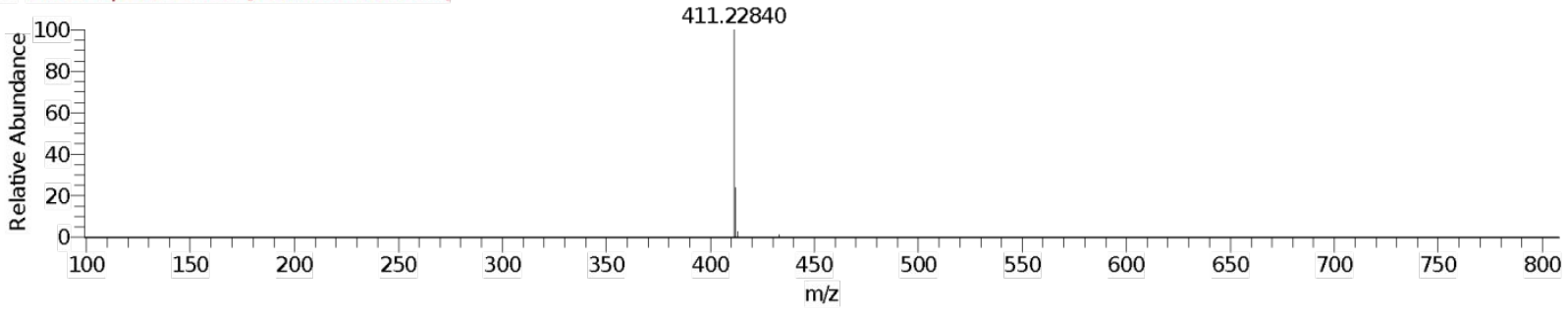


M4 (m/z 409)

RT: $6.00-15.05$ SM: $15 \mathrm{G}$

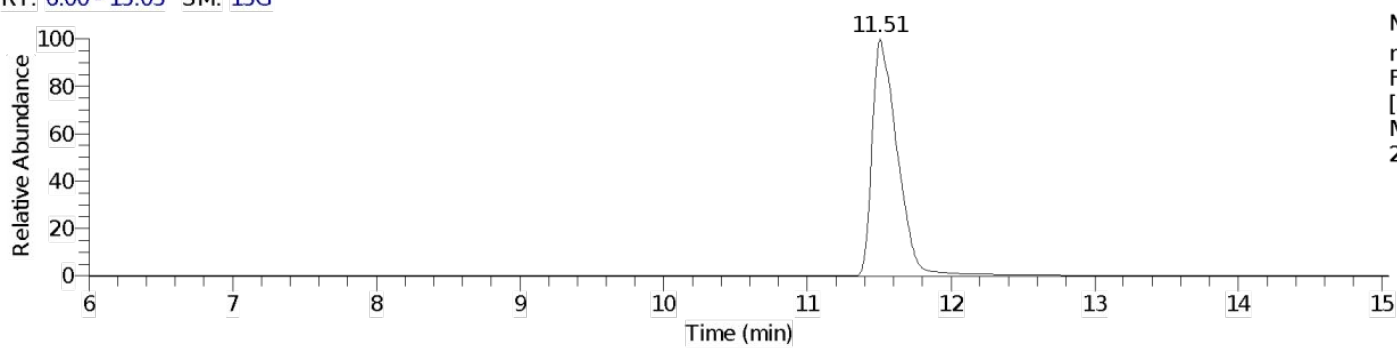

NL: 2.59E 8

$\mathrm{m} / \mathrm{z}=408.50-409.50 \mathrm{~F}$ : FTMS + p ESI Full ms [100.0000-800.0000]

20190709-HF07045-2

20190709-HF07045-2 \#2933-3026 RT: 11.44-11.73 AV: 31 NL: 1.52E8

F: FTMS + p ESI Full ms [100.0000-800.0000]

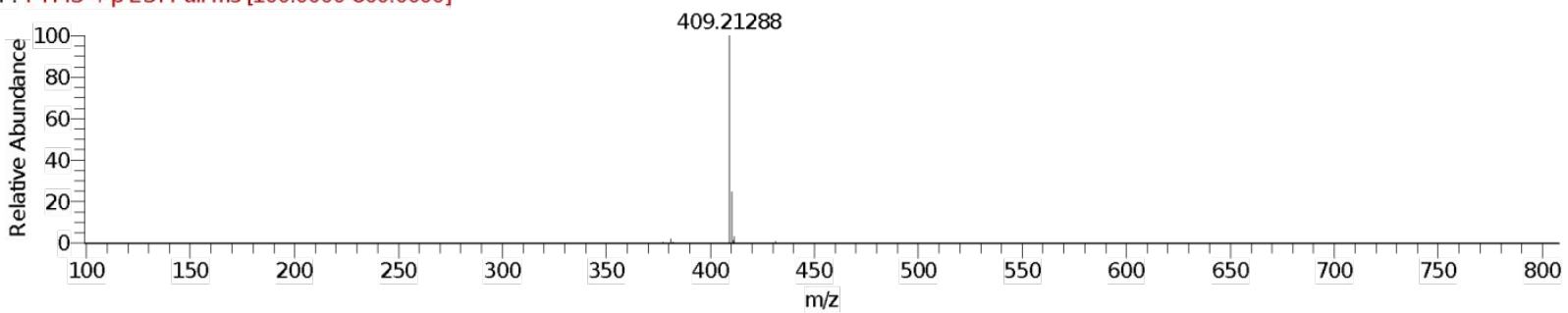

\section{M5 (m/z 411)}

RT: 5.80 - 14.16 SM: $15 G$

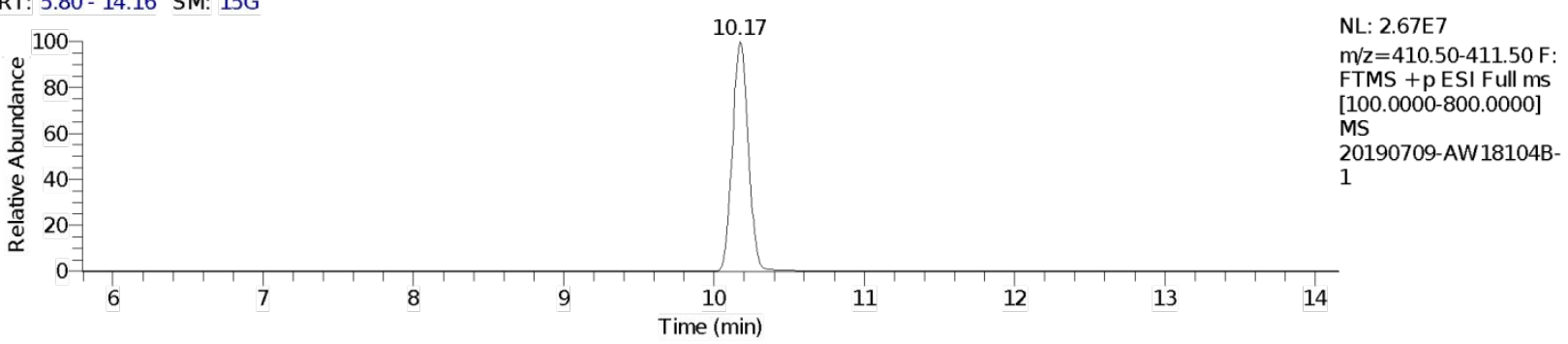

20190709-AW18104B-1 $\# 2562-2600$ RT: 10.12-10.25 AV: 13 NL: $2.06 E 7$

F: FTMS + p ESI Full ms [100.0000-800.0000]

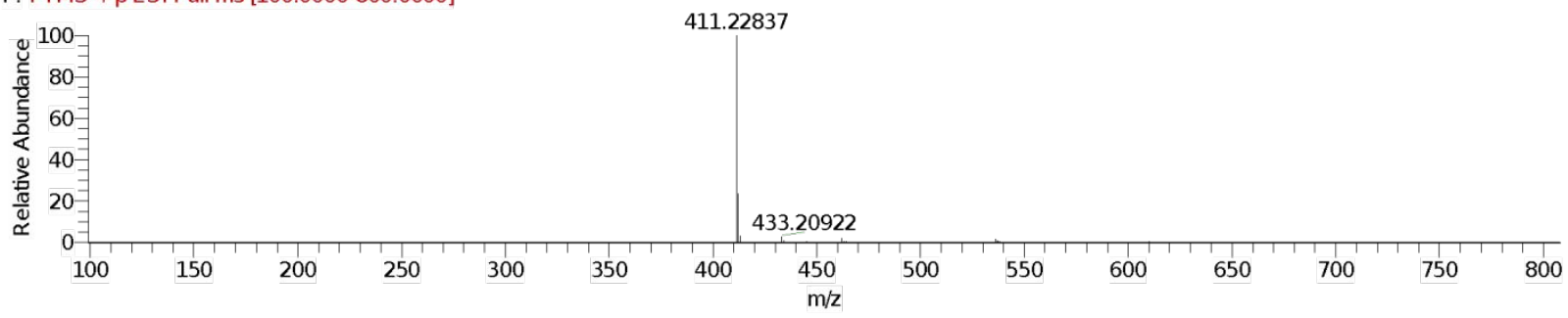




\section{M6-para (m/z 411)}

RT: $7.78-12.73$ SM: $15 G$

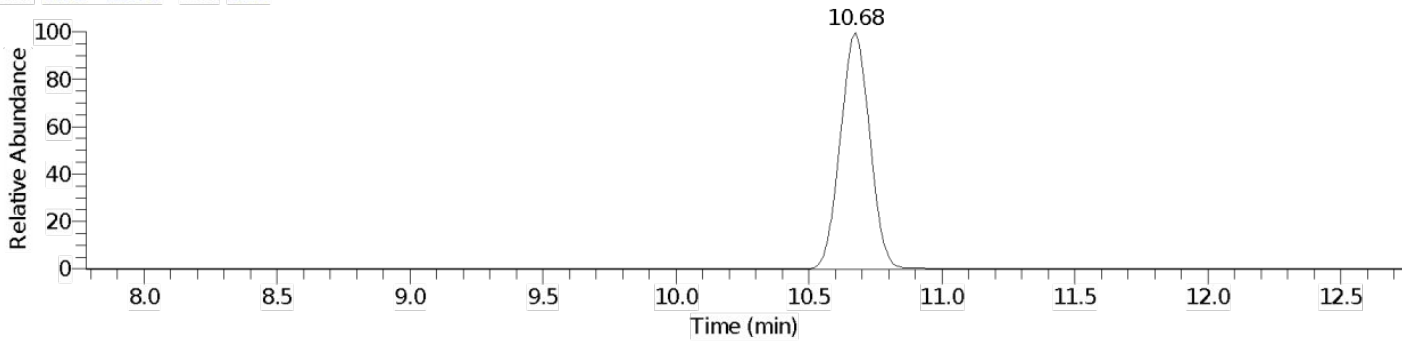

NL: $7.62 \mathrm{E} 7$

$\mathrm{m} / \mathrm{z}=410.50-411.50$ F: FTMS + p ESI Ful

[100.0000-800.0000]

MS HF07052-fs-c

HF07052-fs-c \#3335-3387 RT: 10.61-10.77 AV: 11 NL: 5.35E7

F: FTMS + p ESI Full ms [100.0000-800.0000]

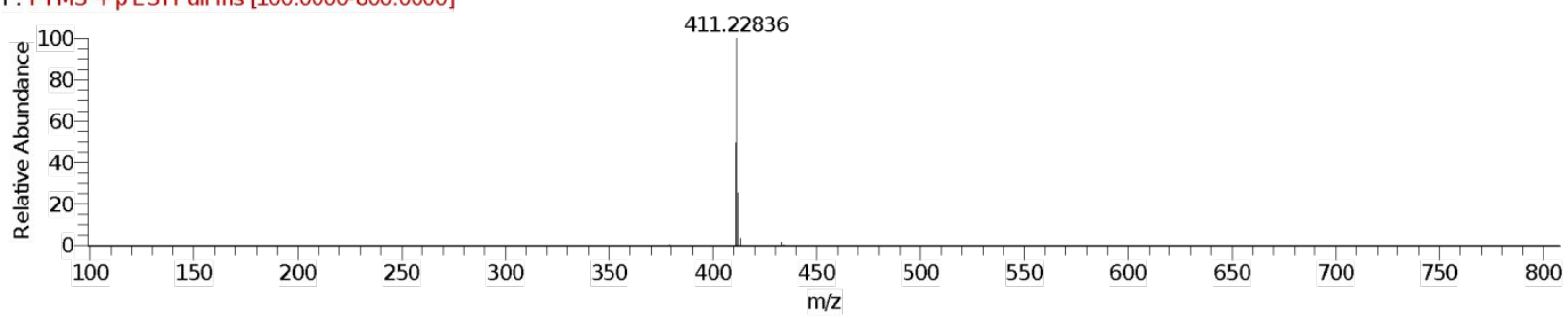

\section{M6-meta $(\mathrm{m} / \mathrm{z}$ 411)}

RT: $7.38-14.53$ SM: $15 G$

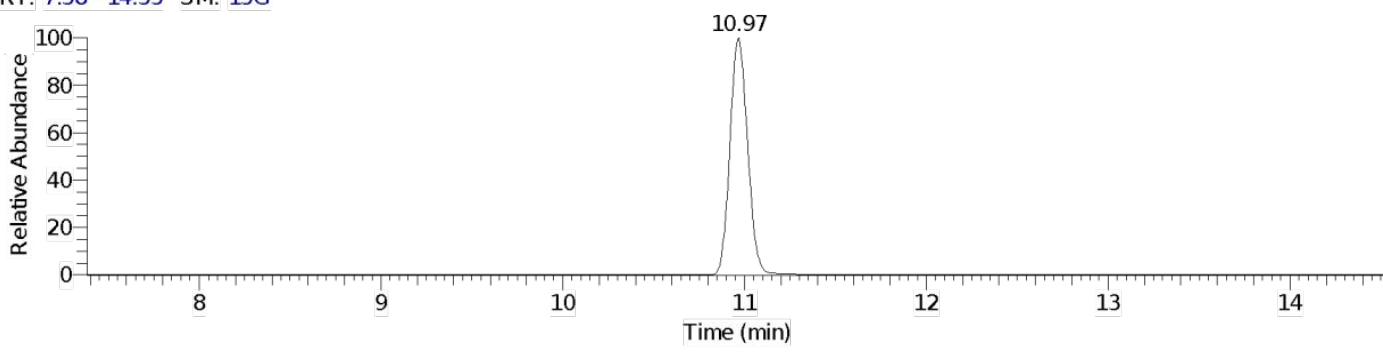

NL: $3.52 E 7$

$\mathrm{m} / \mathrm{z}=410.50-411.50 \mathrm{~F}$ : FTMS + p ESI Full ms [100.0000-800.0000]

20190709-HF 07083-1

20190709-HF07083-1 $\# 2779-2818$ RT: 10.91-11.04 AV: 14 NL: $2.50 E 7$

F: FTMS + p ESI Full ms [100.0000-800.0000]

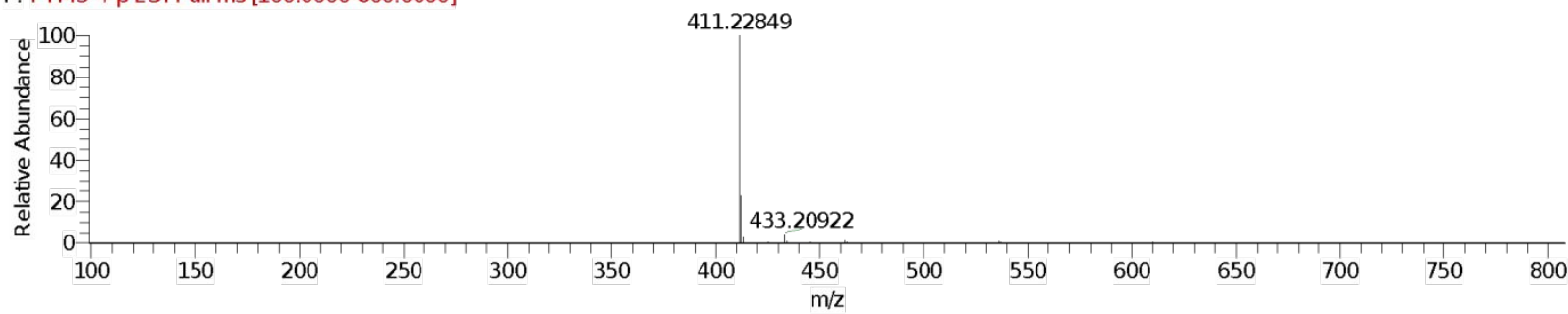




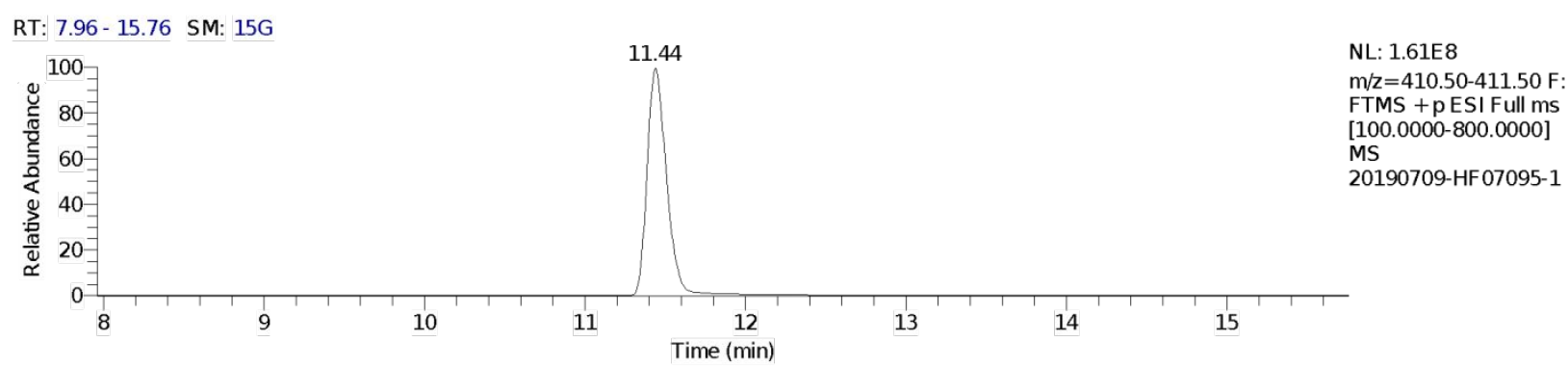

20190709-HF07095-1 \#2901-2970 RT: 11.35-11.59 AV: 23 NL: 8.67E7

F: FTMS + pESI Full ms [100.0000-800.0000]

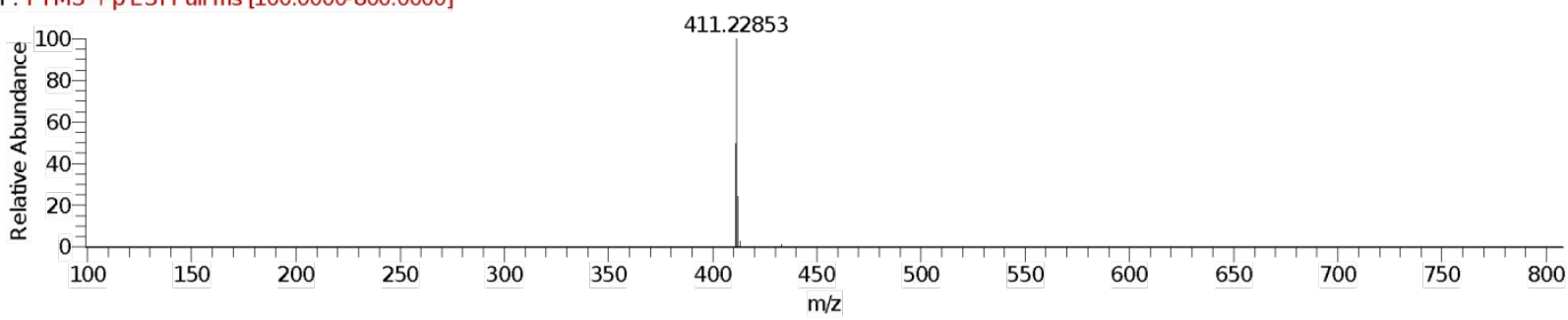

Supporting Figure 16. Metabolism, UHPLC and mass spectral methods and data for synthesized

standards and metabolites.

\section{Metabolism chemicals and reagents}

NADPH ( $\beta$-Nicotinamide adenine dinucleotide 2'-phosphate reduced tetrasodium salt hydrate), magnesium chloride, ammonium formate, and formic acid (FA) were from Sigma-Aldrich (St. Louis, MO, USA). OmniSolv ${ }^{\circ}$ LC-MS acetonitrile, high purity water (B \& J brand) were from VWR International (Radnor, PA, USA). Pooled mixed gender human liver microsomes were from Sekisui XenoTech, LLC (Kansas City, KS, USA) and were stored at $-80^{\circ} \mathrm{C}$ until use. All other chemicals were of the highest grade available.

\section{Incubation of carfentanil with pooled human liver microsomes}

Carfentanil $(10 \mu \mathrm{M})$ was incubated in $200 \mu \mathrm{L}$ of a reaction solution containing $0.1 \mathrm{M}$ potassium phosphate buffer ( $\mathrm{pH} 7.4$ ), $3 \mathrm{mM} \mathrm{MgCl}, 2 \mathrm{mg} / \mathrm{mL}$ human liver microsomal protein. After $5 \mathrm{~min}$ at $37^{\circ} \mathrm{C}, 2 \mathrm{mM} \mathrm{NADPH}$ was added to initiate the reaction. The reactions were performed in triplicate and a control reaction, without liver microsomes, was performed in duplicate. Each reaction was run for 3, 7, 13, 20, 30, 45, 60 and 120 min then quenched by the addition of an equal volume of ice-cold acetonitrile containing internal standard $\left(1 \mu \mathrm{M}\right.$ carfentanil- $\left.d_{5}\right)$. The incubation mixtures were vortexed then centrifuged at $2250 \times \mathrm{g}$ for $10 \mathrm{~min}$. The supernatants were frozen and stored at $-80^{\circ} \mathrm{C}$ until analysis.

\section{Ultra-high performance liquid chromatography-high resolution mass spectrometry (UHPLC- HRMS) conditions}

UHPLC-HRMS was performed on a Thermo-Fisher Scientific Ultimate 3000 HPLC system coupled to an Orbitrap Fusion ${ }^{\mathrm{TM}}$ Tribrid ${ }^{\mathrm{TM}}$ mass spectrometer (Orbitrip Fusion TMS, Thermo-Fisher Scientific, Waltham, MA, USA). Metabolite separation was achieved by using a Kinetex® EVO C18 column $(100 \times 2.1 \mathrm{~mm}, 1.7$ $\mu \mathrm{m}$ particle size, $100 \AA$ pore size, Phenomenex, CA, USA) at a flow rate of $280 \mu \mathrm{L} / \mathrm{min}$. Mobile phase A was $10 \mathrm{mM}$ ammonium formate with $0.1 \% \mathrm{FA}$ and mobile phase $\mathrm{B}$ was acetonitrile with $0.1 \% \mathrm{FA}$. The elution gradient was as follows: $0-1 \mathrm{~min}$, an isocratic elution of $5 \% \mathrm{~B} ; 1-10 \mathrm{~min}$, a linear gradient to $40 \% \mathrm{~B}$; 10-14 min, a linear gradient to $95 \%$ B; $14-15.7 \mathrm{~min}$, an isocratic elution of $95 \%$ B; $15.8 \mathrm{~min}$, a gradient back to $2 \% \mathrm{~B}$. The total run time was $17 \mathrm{~min}$. The injection volume was $5 \mu \mathrm{L}$. The auto sampler chamber was maintained at $4{ }^{\circ} \mathrm{C}$ with a column temperature of $30^{\circ} \mathrm{C}$. 
Heated electrospray ionization (HESI) was utilized in the positive ion mode and carfentanil and its metabolites were analyzed from $\mathrm{m} / \mathrm{z} 100$ to 800 . Orbitrap Fusion TMS has two fragmentation techniques, collision induced dissociation (CID) and higher-energy collisional dissociation (HCD). In this study, HCD was used. The parameters used for the mass spectrometer were: spray voltage, $4100 \mathrm{~V}$; sheath gas flow rate, 40 respective arbitrary unit; aux gas flow rate, 20 respective arbitrary units; ion transfer tube temperature, $325^{\circ} \mathrm{C}$; vaporizer temperature, $300^{\circ} \mathrm{C}$; $\mathrm{MS}^{1}$ detector, Orbitrap; $\mathrm{MS}^{1}$ resolution, 120,000; $\mathrm{MS}^{1}$ scan range, 100-800; $\mathrm{MS}^{1}$ maximum injection time, $100 \mathrm{~ms}$; $\mathrm{MS}^{1}$ automated gain control (AGC) target, 100,000; S-lens RF level, $60 \mathrm{~V}$; MS² HCD collision energy, 30\%; MS² detector, Orbitrap; MS ${ }^{2}$ resolution, 60,000; $\mathrm{MS}^{2} \mathrm{AGC}$ target, 50,000; $\mathrm{MS}^{2}$ maximum injection time, $35 \mathrm{~ms} ; \mathrm{MS}^{2}$ start mass, 50. In all experiments, active internal mass calibration was employed during the analysis. Xcalibur Qual and Quan Browser software were used for the qualitative and quantitative analysis.

\begin{tabular}{|c|c|c|c|c|c|c|c|}
\hline $\begin{array}{l}\text { METABOLI } \\
\text { TES }\end{array}$ & $\begin{array}{l}\% \text { of initial } \\
\text { carfentanil }(2 \mathrm{~h} \\
\text { incubation) }\end{array}$ & RT (min) & $\begin{array}{l}\text { Calculated mass } \\
\text { (molecular ion and } \\
\text { major fragment ions) }\end{array}$ & $\begin{array}{l}\text { Measured } \\
\text { mass }\end{array}$ & $\begin{array}{l}\text { Mass } \\
\text { error } \\
(\mathrm{ppm})\end{array}$ & $\begin{array}{l}\text { Std } \\
\text { measured } \\
\text { mass }\end{array}$ & $\begin{array}{l}\text { Mass } \\
\text { error } \\
(\mathrm{ppm})\end{array}$ \\
\hline M1 & & $8.36-\mathrm{m} / \mathrm{z} 291$ & 291.17032 & 291.17015 & 0.58 & 291.17027 & 0.17 \\
\hline & \multirow{5}{*}{$40 \%$} & & 113.05971 & 113.05976 & -0.44 & 113.05976 & -0.44 \\
\hline & & & 142.08626 & 142.08627 & -0.07 & 142.08627 & -0.07 \\
\hline & & & 146.09643 & 146.09642 & 0.07 & 146.09642 & 0.07 \\
\hline & & & 175.12297 & 175.12297 & 0.00 & 175.12297 & 0.00 \\
\hline & & & 231.14919 & 231.14912 & 0.30 & 231.14912 & 0.30 \\
\hline \multirow[t]{7}{*}{ Potential M7 } & & $9.37-\mathrm{m} / \mathrm{z} 411$ & 411.22783 & 411.22773 & 0.24 & & \\
\hline & & & 113.05971 & 113.05976 & -0.44 & & \\
\hline & & & 170.08117 & 170.08115 & 0.12 & & \\
\hline & & & 262.14377 & 262.14364 & 0.50 & & \\
\hline & & & 295.18049 & 295.18033 & 0.54 & & \\
\hline & & & 317.18597 & 317.18575 & 0.69 & & \\
\hline & & & 351.20670 & 351.20653 & 0.48 & & \\
\hline \multirow[t]{6}{*}{ M5 } & & $\begin{array}{l}10.17-\mathrm{m} / \mathrm{z} \\
411\end{array}$ & 411.22783 & 411.22757 & 0.63 & 411.22837 & -1.31 \\
\hline & & & 113.05971 & 113.05973 & -0.18 & 113.05972 & -0.09 \\
\hline & & & 134.09643 & 134.09625 & 1.34 & 134.09640 & 0.22 \\
\hline & & & 246.14886 & 246.14871 & 0.61 & 246.14870 & 0.65 \\
\hline & & & 279.18558 & 279.18518 & 1.43 & 279.18537 & 0.75 \\
\hline & & & 351.20670 & 351.20644 & 0.74 & 351.20643 & 0.77 \\
\hline \multirow[t]{7}{*}{ M6-para } & & $\begin{array}{l}10.68-\mathrm{m} / \mathrm{z} \\
411\end{array}$ & 411.22783 & 411.22831 & -1.17 & 411.22836 & -1.29 \\
\hline & & & 113.05971 & 113.05964 & 0.62 & 113.05970 & 0.09 \\
\hline & & & 150.09134 & 150.09130 & 0.27 & 150.09125 & 0.60 \\
\hline & & & 202.12264 & 202.12266 & -0.10 & 202.12253 & 0.54 \\
\hline & & & 262.14377 & 262.14365 & 0.46 & 262.14347 & 1.14 \\
\hline & & & 295.18049 & 295.18022 & 0.91 & 295.18004 & 1.52 \\
\hline & & & 351.20670 & 351.20646 & 0.68 & 351.20618 & 1.48 \\
\hline \multirow[t]{6}{*}{ M2 } & & $\begin{array}{l}11.16-\mathrm{m} / \mathrm{z} \\
411\end{array}$ & 411.22783 & 411.22764 & 0.46 & 411.22826 & -1.05 \\
\hline & \multirow{5}{*}{$12 \%$} & & 113.05971 & 113.05975 & -0.35 & 113.05973 & -0.18 \\
\hline & & & 162.09134 & 162.09133 & 0.06 & 162.09128 & 0.37 \\
\hline & & & 202.12264 & 202.12264 & 0.00 & 202.12256 & 0.40 \\
\hline & & & 232.13321 & 232.13314 & 0.30 & 232.13307 & 0.60 \\
\hline & & & 262.14377 & 262.14365 & 0.46 & 262.14356 & 0.80 \\
\hline
\end{tabular}




\begin{tabular}{|c|c|c|c|c|c|c|c|}
\hline & & & 295.18049 & 295.18031 & 0.61 & 295.18017 & 1.08 \\
\hline & & & 351.20670 & 351.20647 & 0.65 & 351.20633 & 1.05 \\
\hline \multirow[t]{12}{*}{ M3-trans } & & $\begin{array}{l}12.71-\mathrm{m} / \mathrm{z} \\
411\end{array}$ & 411.22783 & 411.22769 & 0.34 & 411.22840 & 1.73 \\
\hline & \multirow{11}{*}{$2.50 \%$} & & 105.06988 & 105.06993 & -0.48 & 105.06991 & -0.19 \\
\hline & & & 132.08078 & 132.08076 & 0.15 & 132.08074 & -0.15 \\
\hline & & & 150.09134 & 150.09131 & 0.20 & 150.09129 & -0.13 \\
\hline & & & 202.12264 & 202.12164 & 4.95 & 202.12257 & 4.60 \\
\hline & & & 230.11756 & 230.11750 & 0.26 & 230.11742 & -0.35 \\
\hline & & & 244.13321 & 244.13328 & -0.29 & 244.13304 & -0.98 \\
\hline & & & 247.14410 & 247.14396 & 0.57 & 247.14391 & -0.20 \\
\hline & & & 262.14377 & 262.14357 & 0.76 & 262.14352 & -0.19 \\
\hline & & & 274.14377 & 274.14361 & 0.58 & 274.14353 & -0.29 \\
\hline & & & 303.17032 & 303.17007 & 0.82 & 303.16998 & -0.30 \\
\hline & & & 355.20162 & 355.20141 & 0.59 & 355.20128 & -0.37 \\
\hline \multirow[t]{12}{*}{ M3-cis } & & $\begin{array}{l}12.81-\mathrm{m} / \mathrm{z} \\
411\end{array}$ & 411.22783 & 411.22763 & 0.49 & 411.22830 & 1.63 \\
\hline & & & 105.06988 & 105.06993 & -0.48 & 105.06990 & -0.29 \\
\hline & & & 134.09643 & 134.09643 & 0.00 & 134.09638 & -0.37 \\
\hline & & & 150.09134 & 150.09131 & 0.20 & 150.09127 & -0.27 \\
\hline & & & 202.12264 & 202.12221 & 2.13 & 202.12255 & 1.68 \\
\hline & & & 230.11756 & 230.11746 & 0.43 & 230.11736 & -0.43 \\
\hline & & & 244.13321 & 244.13426 & -4.30 & 244.13301 & -5.12 \\
\hline & & & 262.14377 & 262.14361 & 0.61 & 262.14352 & -0.34 \\
\hline & & & 274.14377 & 274.14363 & 0.51 & 274.14353 & -0.36 \\
\hline & & & 303.17032 & 303.17010 & 0.73 & 303.16998 & -0.40 \\
\hline & & & 335.21179 & 335.21198 & -0.57 & 335.21145 & -1.58 \\
\hline & & & 379.20162 & 379.20138 & 0.63 & 379.20118 & -0.53 \\
\hline \multirow[t]{7}{*}{ M4 } & & $\begin{array}{l}11.51-\mathrm{m} / \mathrm{z} \\
409\end{array}$ & 409.21218 & 409.21203 & 0.37 & 409.21288 & -1.71 \\
\hline & \multirow{6}{*}{$1.90 \%$} & & 113.05971 & 113.05972 & -0.09 & 113.05984 & -1.15 \\
\hline & & & 146.09643 & 146.09637 & 0.41 & 146.09658 & -1.03 \\
\hline & & & 158.09643 & 158.09639 & 0.25 & 158.09650 & -0.44 \\
\hline & & & 202.12264 & 202.12254 & 0.49 & 202.12273 & -0.45 \\
\hline & & & 260.12812 & 260.12743 & 2.65 & 260.12808 & 0.15 \\
\hline & & & 349.19105 & 349.19064 & 1.17 & 349.19087 & 0.52 \\
\hline
\end{tabular}

Supporting Figure 17. MOR assay experimental methods.

\section{Pharmacological assaying materials}

Hank's Balanced Salt Solution (1X), cell growth media (Ham's F-12, MEM Non-Essential Amino Acids Solution, FBS, and G418 selective antibiotic), non-enzymatic dissociation solution (Versene ${ }^{\mathrm{TM}}$ Solution), and HEPES were purchased from Invitrogen (Gathersburg, MD, USA). Forskolin and IBMX were purchased from Sigma-Aldrich (St. Louis, MO, USA). Optiplate 384 white opaque 384-well microplates, TopSeal $^{\mathrm{TM}}$-A adhesive film, and the Lance Ultra cAMP kit were purchased from Perkin Elmer (Waltham, MA, USA). Chinese Hamster Ovary (CHO) K1 cells stably expressing the human mu opioid receptor gene (OP3; MOR) were purchased/licensed from ChanTest Corporation, now Charles River Laboratories (Wilmington, MA, USA). 


\section{Cell culture and transfections}

CHO-K1 cells expressing the human MOR were cultivated in Ham's F12 medium, supplemented with $10 \%$ FBS, 1X NEAA for $24 \mathrm{~h}$ post-thaw, and media replaced at $24 \mathrm{~h}$ by similar media with $0.4 \mathrm{mg} / \mathrm{mL}$ geneticin (G418) selection antibiotic until ready to assay. Subconfluent cells ( $70 \%)$ were used for the assay.

\section{Lance Ultra cAMP assay}

The assay procedure was followed exactly as described in the manufacturer's Assay Development Guidelines and has been reported in the literature..$^{1-3}$ In brief, on the day of the assay, ligand solutions ( $10 \mathrm{mM}$ stocks in dimethylsulfoxide) were diluted into assay buffer and added to the wells of a 384-well Optiplate in triplicate. Cell suspensions (1,000 cells/well) were added and incubated with the ligands for $30 \mathrm{~min}$, followed by the addition of the assay tracer (Eu-cAMP) and antibody (Ulight ${ }^{T M}$ - anti-cAMP) solutions prepared immediately before plating and incubation in the dark for $1 \mathrm{~h}$ at room temperature covered by adhesive film. The plate was then read on a Molecular Devices FlexStation III by exciting the wells with light of $340 \mathrm{~nm}$ and measuring the emission at $615 \mathrm{~nm}$ and 665 $\mathrm{nm}$.

\section{Data analysis}

The measured fluorescence energy transfer ratio $(665 \mathrm{~nm} / 615 \mathrm{~nm})$ was plotted against metabolite concentration in GraphPad Prism v8.1.2 (San Diego, CA, USA) and normalized to the control agonist's DAMGO response. Concentration-response curves were fitted by non-linear regression [agonist] vs. response - variable slope (four parameter) equation:

$Y=$ Bottom $+\left(X^{\text {Hillslope }}\right) \times($ Top - Bottom $) /\left(X^{\text {Hillslope }}+E C_{50}^{\text {Hillslope }}\right)$

Supporting Figure 18. Lance Ultra cAMP assay concentration-response curves.

Data for carfentanil and the eight metabolites synthesized. Data are normalized to the reference compound DAMGO for percent response and are shown as means (error bars represent SEM) of a single representative experiment performed in triplicate. 


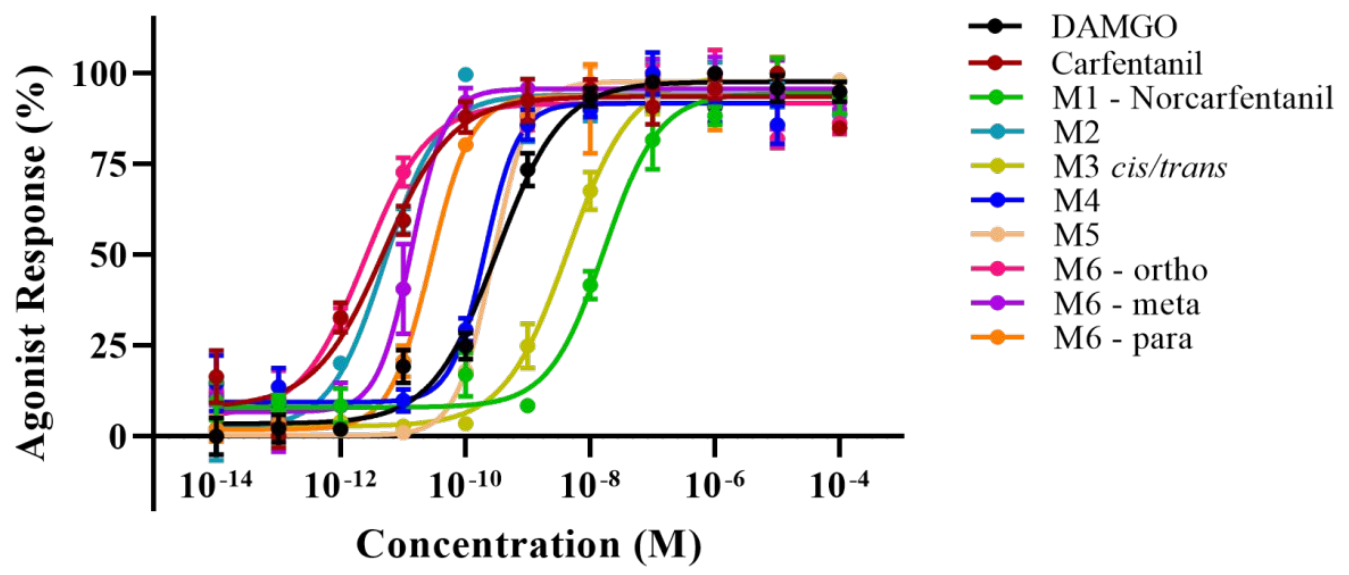

\section{References:}

(1) Livingston, K. E.; Mahoney, J.; Manglik, A.; Kobilka, B.; Sunahara, R.; Traynor, J. R. Efficacy at the Mu Opioid Receptor: Insights from Orthosteric and Allosteric Ligands. Faseb J. 2016, 30, 1.

(2) Perkin Elmer. Lance Ultra cAMP Assay Development Guidelines. Version2. Catalogue Number TRF0263: 10,000 assay point kit. 2010.

(3) LANCE Ultra cAMP: A New, Two-Component TR-FRET cAMP Assay for $\mathrm{HTS}_{\mathrm{T}}$ of $\mathrm{G}_{\mathrm{s}}{ }^{-}$and $\mathrm{G}_{\mathrm{i}} \mathrm{-}^{-}$ coupled Receptors. SBS $16^{\text {th }}$ Annual Conference (2010). 